\title{
Capital Control, Exchange Rate Regime, and Monetary Policy: Indeterminacy and Bifurcation
}

\author{
William A. Barnett, University of Kansas, Lawrence \\ Center for Financial Stability, NY City \\ ICEMR Institute for Nonlinear Dynamical Inference, Moscow \\ IC $^{2}$ Institute, University of Texas, Austin \\ and \\ Jingxian Hu, University of Kansas, Lawrence
}

September 16, 2017

\begin{abstract}
Will capital controls enhance macro economy stability? How will the results be influenced by the exchange rate regime and monetary policy reaction? Are the consequences of policy decisions involving capital controls easily predictable, or more complicated than may have been anticipated? We will answer the above questions by investigating the macroeconomic dynamics of a small open economy. In recent years, these matters have become particularly important to emerging market economies, which have often adopted capital controls. We especially investigate two dynamical characteristics: indeterminacy and bifurcation. Four cases are explored, based on different exchange rate regimes and monetary policy rules.

With capital controls in place, we find that indeterminacy depends upon how inflation and output gap coordinate with each other in their feedback to interest rate setting in the Taylor rule. When forward-looking, both passive and positive monetary policy feedback can lead to indeterminacy. Compared with flexible exchange rates, fixed exchange rate regimes produce more complex indeterminacy conditions, depending upon the stickiness of prices and the elasticity of substitution between labor and consumption. We find Hopf bifurcation under capital control with fixed exchange rates and current-looking monetary policy. To determine empirical relevance, we test indeterminacy empirically using Bayesian estimation. Fixed exchange rate regimes with capital controls produce larger posterior probability of the indeterminate region than a flexible exchange rate regime. Fixed exchange rate regimes with current-looking monetary policy lead to several kinds of bifurcation under capital controls.
\end{abstract}

We provide monetary policy suggestions on achieving macroeconomic stability through financial regulation.

JEL Code: F41, F31, F38, E52, C11, C62

Key Words: Capital controls, open economy monetary policy, exchange rate regimes, Bayesian methods, bifurcation, indeterminacy. 


\section{Introduction}

Since the Great Recession following the 2008 financial crisis, the potential problems caused by free capital movements among countries have drawn attention to the relationship between financial regulation, capital controls, and macroeconomic stability. Some researchers support capital controls with prudential macroeconomic policy. According to that view, capital controls can mitigate systemic risk, reduce business cycle volatility, and increase macroeconomic stability. Related research includes Farhi and Werning (2012, 2014), Korinek (2011, 2014), Ostry et al. (2012), and Magud et al. (2012).

According to Mundell’s (1963) “impossible trinity” in international economics, an open economy cannot simultaneously have independent monetary policy, fixed exchange rates, and free capital movement. ${ }^{1}$ Under prudential macroeconomic policy with control of capital flows, we investigate combinations of exchange rate regimes and monetary policies that could stabilize the economy. Is it possible that the choices of exchange rate regime and monetary policy could generate instability and increased volatility, even though capital flows are controlled? How to make such policy decisions and to what extent the policy should be adjusted are challenging questions relevant to all monetary authorities.

In this paper, we explore the dynamics of an economic system with capital controls. We investigate the possible instability or non-uniqueness of equilibria and their relevancy to policy under capital controls. In contrast, Farhi and Werning (2012, 2014) and Korinek (2011, 2014) study welfare implications of capital controls from a theoretic perspective, while Ostry et al. (2012) and Magud et al. (2012) investigate the relationship of capital controls to macroeconomic stability using empirical methods. Our contribution is to investigate dynamical characteristics with emphasis on indeterminacy and bifurcation.

Indeterminacy occurs if the equilibrium of an economic system is not unique, resulting in the existence of multiple equilibria. Under those circumstances, consumers' and firms' forecasts of macroeconomic variables, such as output and inflation rates, can lead to the phenomenon of "selffulfilling prophecy.” The economy can move from one equilibrium to another. A new equilibrium, driven by economic agents' beliefs, could be a better one or a worse one. If capital controls signal to people that they are protected from the risk of international financial market volatility, then the beliefsdriven equilibrium may be better than without those controls. Alternatively, if imposition of capital controls produces panic and induces evasion of the controls, the equilibrium can be worse than

\footnotetext{
${ }^{1}$ Mundell's (1963) “impossible trinity” is alternatively often called the "Mundell-Fleming trilemma” to recognize the relevancy of Fleming (1962).
} 
equilibrium without capital controls. As a result, we investigate existence of multiple equilibria in an open economy with different exchange rate regimes and monetary policies. We also empirically examine indeterminacy using Bayesian methods to estimate the probability of the indeterminacy region. We also acquire the posterior estimates of parameters and the impulse responses under both fundamental shocks and sunspot shocks.

We find that the existence of indeterminacy depends upon how inflation and output gap coordinate with each other in their feedback to interest rate setting in the Taylor rule. Our results expand the conclusions of previous literature on indeterminacy and monetary policy to the case of capital controls. See, e.g., Cochrane (2011) and Benhabib et al. (2001). When monetary policy is forward looking with capital controls, we find that both passive feedback and positive feedback can generate indeterminacy. ${ }^{2}$

The exchange rate regime can alter the conditions for indeterminacy. Compared with flexible exchange rates, a fixed exchange regime produces more complex conditions, depending on the stickiness of price setting and the elasticity of substitution between labor and consumption. Interestingly, the degree of openness does not play a lare role in our results. This difference from previous literature evidently is associated with the control of international capital mobility.

We introduce into our model incompleteness of international capital markets and staggered price setting, in contrast with Airaudo and Zanna (2012), who analyze global equilibrium determinacy in a flexible-price open economy with active interest rate rules on inflation. Benhabib and Farmer (1999) find that staggered price setting can cause indeterminacy to arise. We find that when price is close to flexible with capital controls, indeterminacy is possible.

The other primary objective of our paper is to investigate existence of bifurcation phenomena in an open economy with capital controls. Bifurcation is definited to occur, if a qualitative change in dynamics occurs, when the bifurcation boundary is crossed by the deep parameters of the economy's structure. Such deep parameters are not only those of private tastes and technology, but also of monetary policy rules. Such qualitative change can be between instability and stability. But the change can also be between different kinds of instability or between different kinds of stability, such as monotonic stability and periodic damped stability, or multiperiodic damped stabilitiy. Existence of bifurcation boundaries can motivate policy intervention. A slight change to the parameters of private tastes or

\footnotetext{
${ }^{2}$ With passive feedback, the parameter multiplied by inflation or output gap in Taylor rule is defined to be between 0 and 1 . With positive feedback, the parameter is larger than 1.
} 
technology or to the parameters of central bank feedbacks of output and inflation to policy instruments can induce a fundamental change in the nature of the economy's dynamics.

The previous literature investigating bifurcation without capital controls includes Barnett and Duzhak (2008, 2010, 2014), Barnett and Eryilmaz (2013, 2014), and the survey paper Barnett and Chen (2015). In contrast, we introduce capital controls and an exchange rate peg. Without capital controls, Woodford (1986, 1992) and Franke (1992) find that capital market imperfections can lead to more complex dynamics than perfect capital markets. We find that there can exist Hopf bifurcation under capital controls, fixed exchange rates, and current-looking monetary policy. We determine the conditions under which the monetary policy rule or private deep parameters will generate instability. We encounter several kinds of bifurcation, when the model's parameters are estimated by Bayesian methods.

This paper is structured as follows. We illustrate the model in Section 2 and derive the equilibria in Section 3. The dynamical systems under different exchange rate regimes and monetary policies are discussed in Section 4. In Sections 5 and 6, we analyze the conditions for indeterminacy and bifurcation. We discuss the economic implications in Section 7. In Sections 8 and 9, we test indeterminacy empirically and locate bifurcation boundaries numerically. Section 10 is the conclusion.

\section{Model}

In light of Gali and Monacelli (2005) and Farhi and Werning (2012, 2014), our model is an open economy New Keynesian model consisting of a small open economy that imposes capital controls and chooses between flexible exchange rates and fixed exchange rates. Compared with the Mundell Fleming IS-LM-BP model, the New Keynesian model has solid micro-foundation on both the demand side and the supply side. As a result, we are able to analyze the influence of the deep structural parameters on the economy's dynamics.

In contrast with Farhi and Werning $(2012,2014)$, we choose the discrete time version of the linear rational expectations model, instead of the continuous time model, to facilitate analyzing the indeterminacy and bifurcation conditions. For analyzing indeterminacy, the linear rational expectations model automatically fixes the list of predetermined variables, thereby eliminating the need to differentiate between predetermined variables and jump variables. ${ }^{3}$ Discrete time also permits location of bifurcation boundaries in linear system, as in Barnett and Duzhak (2008, 2010, and 2014) and Barnett and Eryilmaz (2013, 2014). In addition, rational expectations allows us to differentiate between

\footnotetext{
${ }^{3}$ See Sims (2002).
} 
fundamental shocks and non-fundamental forecasting errors. Farmer et al. (2015) and Beyer and Farmer (2004) find methods to change the system from indeterminate to determinate by moving the nonfundamental forecasting errors. The number of those errors equals the degree of indeterminacy to the fundamental shocks set. In the rational expectations model, it is possible for beliefs to drive the economy to another path that converges to a steady state, producing a self-fulfilling prophecy. In principle, it is possible to regulate or influence those beliefs. This phenomenon is different from "animal spirit.”

There is a continuum of small open economies, indexed along the unit interval. Different economies share identical preferences, technology, and market structure. Following the conventions in this literature, we use variables without $i$-index to refer to the small open economy being modelled. Variables with $i$-index refer to variables in economy $i$, among the continuum of economies making up the world economy. Variables with a star correspond to the world economy as a whole, while $j$ denotes a particular good within an economy.

\subsection{Households}

A representative household seeks to maximize

$$
E_{0} \sum_{t=0}^{\infty} \beta^{t}\left[\frac{C_{t}^{1-\sigma}}{1-\sigma}-\frac{N_{t}^{1+\varphi}}{1+\varphi}\right]
$$

where $N_{t}$ denotes hours of labor, $C_{t}$ is a composite consumption index defined by

$$
C_{t} \equiv\left[(1-\alpha)^{\frac{1}{\eta}}\left(C_{H, t}\right)^{\frac{\eta-1}{\eta}}+\alpha^{\frac{1}{\eta}}\left(C_{F, t}\right)^{\frac{\eta-1}{\eta}}\right]^{\frac{\eta}{\eta-1}}
$$

with $C_{H, t} \equiv\left(\int_{0}^{1} C_{H, t}(j)^{\frac{\varepsilon-1}{\varepsilon}} d j\right)^{\frac{\varepsilon}{\varepsilon-1}}, C_{F, t} \equiv\left(\int_{0}^{1}\left(C_{i, t}\right)^{\frac{\gamma-1}{\gamma}} d i\right)^{\frac{\gamma}{\gamma-1}}, C_{i, t} \equiv\left(\int_{0}^{1} C_{i, t}(j)^{\frac{\varepsilon-1}{\varepsilon}} d j\right)^{\frac{\varepsilon}{\varepsilon-1}}$.

The parameter $\varepsilon>1$ denotes the elasticity of substitution among goods within any given country. The parameter $\alpha \in[0,1]$ denotes the degree of home bias in preferences and is an index of openness, while $\eta>0$ measures the elasticity of substitution between domestic and foreign goods, and $\gamma$ measures the elasticity of substitution among goods produced in different countries.

The household's budget constraint takes the form 


$$
\begin{aligned}
& \int_{0}^{1} P_{H, t}(j) C_{H, t}(j) d j+\int_{0}^{1} \int_{0}^{1} P_{i, t}(j) C_{i, t}(j) d j d i+E_{t}\left\{Q_{t, t+1} D_{t+1}\right\}+\int_{0}^{1} E_{t}\left\{\mathcal{E}_{i, t} Q_{t, t+1}^{i} D_{t+1}^{i}\right\} d i \\
& \leq W_{t} N_{t}+T_{t}+D_{t}+\int_{0}^{1}\left(\frac{1+\tau_{t}}{1+\tau_{t}^{i}}\right) \mathcal{E}_{i, t} D_{t}^{i} d i
\end{aligned}
$$

where $D_{t+1}$ is holding of the home portfolio, consisting of shares in firms. Holding of country $i$ 's portfolio is $D_{t+1}^{i}$, while $Q_{t, t+1}$ is the price of the home portfolio, and $Q_{t, t+1}^{i}$ is the price of country $i$ 's portfolio. The nominal wage is $W_{t}$. The lump-sum transfer/tax at $t$ is $T_{t}$. We model the capital control, following Farhi and Werning (2014), with $\tau_{t}$ denoting the subsidy on capital outflows (tax on capital inflows) in home country and $\tau_{t}^{i}$ denoting the subsidy on capital outflows (tax on capital inflows) in country $i$. We assume that country $i$ does not impose capital control, so that $\tau_{t}^{i}=0$. Taxes on capital inflows are rebated as a lump sum to households. We introduce variables that capture the dynamics of capital control, $\tau_{t}$, where $1+\tau_{t+1} \equiv \frac{\Delta_{t+1}}{\Delta_{t}} \equiv \frac{\Theta_{t+1}^{\sigma}}{\Theta_{t}^{\sigma}}$.

The optimal allocation of any given expenditure within each category of goods yields the demand functions, $C_{H, t}(j)=\left(\frac{P_{H, t}(j)}{P_{H, t}}\right)^{-\varepsilon} C_{H, t}$ and $C_{i, t}(j)=\left(\frac{P_{i, t}(j)}{P_{i, t}}\right)^{-\varepsilon} C_{i, t}$, where $P_{H, t} \equiv\left(\int_{0}^{1} P_{H, t}(j)^{1-\varepsilon} d j\right)^{\frac{1}{1-\varepsilon}}$ and $P_{i, t} \equiv\left(\int_{0}^{1} P_{i, t}(j)^{1-\varepsilon} d j\right)^{\frac{1}{1-\varepsilon}}$.

So

$\int_{0}^{1} P_{H, t}(j) C_{H, t}(j) d j=P_{H, t} C_{H, t}$ and $\int_{0}^{1} P_{i, t}(j) C_{i, t}(j) d j=P_{i, t} C_{i, t}$.

The optimal allocation of expenditures on imported goods by country of origin implies $C_{i, t}=\left(\frac{P_{i, t}}{P_{F, t}}\right)^{-\gamma} C_{F, t}$, where $P_{F, t} \equiv\left(\int_{0}^{1} P_{i, t}{ }^{1-\gamma} d i\right)^{\frac{1}{1-\gamma}}$,

so that

$\int_{0}^{1} P_{i, t} C_{i, t} d i=P_{F, t} C_{F, t}$ 
The optimal allocation of expenditures between domestic and imported goods is given by $C_{H, t}=(1-\alpha)\left(\frac{P_{H, t}}{P_{t}}\right)^{-\eta} C_{t}$ and $C_{F, t}=\alpha\left(\frac{P_{F, t}}{P_{t}}\right)^{-\eta} C_{t}$, where $P_{t} \equiv\left[(1-\alpha)\left(P_{H, t}\right)^{1-\eta}+\alpha\left(P_{F, t}\right)^{1-\eta}\right]^{\frac{1}{1-\eta}}$,

so that

$P_{H, t} C_{H, t}+P_{F, t} C_{F, t}=P_{t} C_{t}$

The effective nominal exchange rate is devined by $\mathcal{E}_{t}=\frac{\int_{0}^{1} \mathcal{E}_{i, t} D_{t}^{i} d i}{\int_{0}^{1} D_{t}^{i} d i}$. Hence

we have $\int_{0}^{1} \mathcal{E}_{i, t} D_{t}^{i} d i=\mathcal{E}_{t} \int_{0}^{1} D_{t}^{i} d i=\mathcal{E}_{t} D_{t}^{*}$ and

$\int_{0}^{1} \mathcal{E}_{i, t} Q_{t, t+1}^{i} D_{t+1}^{i} d i=\int_{0}^{1} \mathcal{E}_{t} Q_{t, t+1}^{i} D_{t+1}^{*} d i=\mathcal{E}_{t} D_{t+1}^{*} \int_{0}^{1} Q_{t, t+1}^{i} d i=\mathcal{E}_{t} D_{t+1}^{*} Q_{t, t+1}^{*}$

Thus the budget constraint can be rewritten as

$$
P_{t} C_{t}+E_{t}\left\{Q_{t, t+1} D_{t+1}\right\}+E_{t}\left\{\mathcal{E}_{t} Q_{t, t+1}^{*} D_{t+1}^{*}\right\} \leq W_{t} N_{t}+T_{t}+D_{t}+\left(1+\tau_{t}\right) \mathcal{E}_{t} D_{t}^{*}
$$

Maximizing utility of a household subject to its budget constraint yields two Euler equations:

$$
\begin{aligned}
& \beta E_{t}\left\{\left(\frac{C_{t+1}}{C_{t}}\right)^{-\sigma}\left(\frac{P_{t}}{P_{t+1}}\right)\left(\frac{1}{Q_{t, t+1}}\right)\right\}=1, \\
& \beta E_{t}\left\{\left(\frac{C_{t+1}}{C_{t}}\right)^{-\sigma}\left(\frac{P_{t}}{P_{t+1}}\right)\left(\frac{\mathcal{E}_{t+1}}{\mathcal{E}_{t}}\right)\left(1+\tau_{t+1}\right)\left(\frac{1}{Q_{t, t+1}^{*}}\right)\right\}=1 .
\end{aligned}
$$

The log-linearized form is

$$
\begin{aligned}
& c_{t}=E_{t}\left\{c_{t+1}\right\}-\frac{1}{\sigma}\left(r_{t}-E_{t}\left\{\pi_{t+1}\right\}-\rho\right), \\
& c_{t}=E_{t}\left\{c_{t+1}\right\}-\frac{1}{\sigma}\left(r_{t}^{*}+\left[E_{t}\left\{e_{t+1}\right\}-e_{t}\right]+E_{t}\left\{\tau_{t+1}\right\}-E_{t}\left\{\pi_{t+1}\right\}-\rho\right),
\end{aligned}
$$

where $\left(R_{t}\right)^{-1}=E_{t}\left\{Q_{t, t+1}\right\}$ and $\left(R_{t}^{*}\right)^{-1}=E_{t}\left\{Q_{t, t+1}^{*}\right\}$ and

$$
\pi_{t+1} \equiv p_{t+1}-p_{t} \equiv \log P_{t+1}-\log P_{t}
$$


For the representative household in country $i$, the problem is to maximize

$E_{0} \sum_{t=0}^{\infty} \beta^{t}\left[\frac{C^{i 1-\sigma}}{1-\sigma}-\frac{N^{i 1+\varphi}}{1+\varphi}\right]$

subject to the budget constraint

$P_{t}^{i} C_{t}^{i}+E_{t}\left\{Q_{t, t+1}^{i} D_{t+1}^{i}\right\}+E_{t}\left\{\frac{Q_{t, t+1}^{i^{*}} D_{t+1}^{i^{*}}}{\mathcal{E}_{i, t}}\right\} \leq W_{t}^{i} N_{t}^{i}+T_{t}^{i}+D_{t}^{i}+\frac{D_{t}^{i^{*}}}{\mathcal{E}_{i, t}}$

Notice that there is no capital control in country $i$.

The first order conditions also provides us with two Euler equations

$\beta E_{t}\left\{\left(\frac{C_{t+1}^{i}}{C_{t}^{i}}\right)^{-\sigma}\left(\frac{P_{t}^{i}}{P_{t+1}^{i}}\right)\left(\frac{1}{Q_{t, t+1}^{i}}\right)\right\}=1$,
$\beta E_{t}\left\{\left(\frac{C_{t+1}^{i}}{C_{t}^{i}}\right)^{-\sigma}\left(\frac{P_{t}^{i}}{P_{t+1}^{i}}\right)\left(\frac{\mathcal{E}_{i, t}}{\mathcal{E}_{i, t+1}}\right)\left(\frac{1}{Q_{t, t+1}^{i *}}\right)\right\}=1$,

where $\mathcal{Q}_{i, t} \equiv \frac{\mathcal{E}_{i, t} P_{t}^{i}}{P_{t}}$ is the real exchange rate.

Combined with the two Euler equations for the home country, we get

$\frac{Q_{t, t+1}^{*}}{Q_{t, t+1}}=\frac{\mathcal{E}_{t+1}}{\mathcal{E}_{t}}\left(1+\tau_{t+1}\right)$,
$\frac{Q_{t, t+1}^{i *}}{Q_{t, t+1}^{i}}=\frac{\mathcal{E}_{i, t}}{\mathcal{E}_{i, t+1}}$

$\left(\frac{C_{t+1}}{C_{t}}\right)=\left(\frac{C_{t+1}^{i}}{C_{t}^{i}}\right)\left[\frac{\mathcal{Q}_{i, t+1}\left(1+\tau_{t+1}\right)}{\mathcal{Q}_{i, t}}\right]^{\frac{1}{\sigma}}=\left(\frac{C_{t+1}^{i}}{C_{t}^{i}}\right)\left[\frac{\mathcal{Q}_{i, t+1} \Delta_{t+1}}{\mathcal{Q}_{i, t} \Delta_{t}}\right]^{\frac{1}{\sigma}}$,

where we define $\Delta$ and $\Theta$ to be the variables that captures the dynamics of $\tau_{t}$, such that

$1+\tau_{t+1} \equiv \frac{\Delta_{t+1}}{\Delta_{t}} \equiv \frac{\Theta_{t+1}^{\sigma}}{\Theta_{t}^{\sigma}}$ 
Taking the log we get $\tau_{t+1}=\sigma\left(\theta_{t+1}-\theta_{t}\right)$,

resulting in the Backus-Smith condition,

$$
C_{t}=\Theta_{t} C_{t}^{i} \mathcal{Q}_{i, t}^{\frac{1}{\sigma}}
$$

Taking logs on both sides and integrating over $i$, we get

$c_{t}=c_{t}^{*}+\frac{1}{\sigma} q_{t}+\theta_{t}$

\subsection{Uncovered Interest Parity, Purchasing Power Parity, Terms of Trade, and Exchange Rate}

The pricing equation for foreign bonds and domestic bonds are respectively

$$
\begin{aligned}
& \left(R_{t}^{*}\right)^{-1}=E_{t}\left\{Q_{t, t+1}^{*}\right\}, \\
& \left(R_{t}\right)^{-1}=E_{t}\left\{Q_{t, t+1}\right\} .
\end{aligned}
$$

We combine them to get the Uncovered Interest Parity conditions,

$$
E_{t}\left\{Q_{t, t+1} R_{t}-Q_{t, t+1}^{*} R_{t}^{*}\right\}=0
$$

$R_{t}=\left(1+\tau_{t+1}\right) R_{t}^{*} \frac{\mathcal{E}_{t+1}}{\mathcal{E}_{t}}$

Taking logs on both sides, we get

$r_{t}-r_{t}^{*}=E_{t}\left\{\tau_{t+1}\right\}+E_{t}\left\{e_{t+1}\right\}-e_{t}$

where $e_{t} \equiv \int_{0}^{1} e_{t}^{i} d i$ is the log nominal effective exchange rate.

The bilateral terms of trade between the domestic country and country $i$ are

$S_{i, t} \equiv \frac{P_{i, t}}{P_{H, t}}$.

The effective terms of trade are 
$S_{t} \equiv \frac{P_{F, t}}{P_{H, t}}=\left(\int_{0}^{1} S_{i, t}^{1-\gamma} d i\right)^{\frac{1}{1-\gamma}}$

Log linearizing we get

$S_{t} \equiv p_{F, t}-p_{H, t}$,

$S_{t}=\int_{0}^{1} S_{i, t} d i$ (when $\left.\gamma=1\right)$.

Under the purchasing power parity condition, $P_{H, t}=P_{F, t}$, so that $S_{t}=1$.

Log linearizing, $P_{t} \equiv\left[(1-\alpha)\left(P_{H, t}\right)^{1-\eta}+\alpha\left(P_{F, t}\right)^{1-\eta}\right]^{\frac{1}{1-\eta}}$ becomes

$p_{t} \equiv(1-\alpha) p_{H, t}+\alpha p_{F, t}=p_{H, t}+\alpha s_{t}$, when $\eta=1$.

It follows that

$\pi_{t}=\pi_{H, t}+\alpha\left(s_{t}-s_{t-1}\right)$

and

$E_{t}\left\{\pi_{t+1}\right\}=E_{t}\left\{\pi_{H, t+1}\right\}+\alpha\left[E_{t}\left\{s_{t+1}\right\}-s_{t}\right]$.

The bilateral nominal exchange rate is defined by the law of one price,

$P_{i, t}(j)=\mathcal{E}_{i, t} P_{i, t}^{i}(j)$

where $P_{i, t}^{i}(j)$ is the price of country i's good $j$, expressed in country i's currency.

It follows that $P_{i, t}=\mathcal{E}_{i, t} P_{i, t}^{i}$. The nominal effective exchange rate is defined as

$\mathcal{E}_{t} \equiv\left(\int_{0}^{1} \mathcal{E}_{i, t}^{1-\gamma} d i\right)^{\frac{1}{1-\gamma}}$

Log linearizing $P_{F, t} \equiv\left(\int_{0}^{1} P_{i, t}{ }^{1-\gamma} d i\right)^{\frac{1}{1-\gamma}}$ and substituting $P_{i, t}$ into $P_{F, t}$, we get 
$p_{F, t}=\int_{0}^{1}\left(e_{i, t}+p_{i, t}^{i}\right) d i=e_{t}+p_{t}^{*}$

where $p_{t}^{*} \equiv \int_{0}^{1} p_{i, t}^{i} d i$ is the log world price index. Combining the previous result with terms of trade, we get

$s_{t}=e_{t}+p_{t}^{*}-p_{H, t}$.

The real exchange rate is defined as $\mathcal{Q}_{i, t} \equiv \frac{\mathcal{E}_{i, t} P_{t}^{i}}{P_{t}}$.

We can rewrite the uncovered interest parity condition as

$r_{t}-r_{t}^{*}=E_{t}\left\{\tau_{t+1}\right\}+E_{t}\left\{e_{t+1}\right\}-e_{t}$

Since $\tau_{t+1}=\sigma\left(\theta_{t+1}-\theta_{t}\right)$ and $e_{t}=s_{t}+p_{H, t}-p_{t}^{*}$, it follows that

$r_{t}-r_{t}^{*}=\sigma\left[E_{t}\left\{\theta_{t+1}\right\}-\theta_{t}\right]+\left[E_{t}\left\{s_{t+1}\right\}-s_{t}\right]+E_{t}\left\{\pi_{H, t+1}\right\}-E_{t}\left\{\pi_{t+1}^{*}\right\}$.

\subsection{Firms}

The supply side in this paper is the same as in Gali and Monacelli (2005). Details of the derivation can be found in their paper.

A representative firm in the home country has a linear technology,

$Y_{t}(j)=A_{t} N_{t}(j)$

$$
\begin{aligned}
& Y_{t} \equiv\left[\int_{0}^{1} Y_{t}(j)^{1-\frac{1}{\varepsilon}} d j\right]^{\frac{\varepsilon}{\varepsilon-1}}, \\
& Z_{t} \equiv \int_{0}^{1} \frac{Y_{t}(j)}{Y_{t}} d j, \\
& N_{t} \equiv \int_{0}^{1} N_{t}(j) d j=\frac{Y_{t} Z_{t}}{A_{t}} .
\end{aligned}
$$

The firm follows staggered-price setting, as in Calvo's (1983) model. Each period, $1-\omega$ of firms set new prices. The pricing decision is forward-looking. Firms set the price as a mark-up over a weighted average of expected future marginal costs. As $\omega \rightarrow 0$, the price approaches flexibility. 
The dynamics of domestic inflation are given by

$$
\pi_{H, t}=\beta E_{t}\left\{\pi_{H, t+1}\right\}+\lambda \widehat{m c_{t}}
$$

where

$$
\lambda \equiv \frac{(1-\beta \omega)(1-\omega)}{\omega}
$$

\section{Equilibrium}

In this section, we assume that $\sigma=\eta=\gamma=1$ (Cole-Obstfeld case).

\subsection{Demand Side}

The market clearing condition in the representative small open economy is

$$
\begin{aligned}
Y_{t}(j) & =C_{H, t}(j)+\int_{0}^{1} C_{H, t}^{i}(j) d i \\
& =\left(\frac{P_{H, t}(j)}{P_{H, t}}\right)^{-\varepsilon}\left[(1-\alpha)\left(\frac{P_{H, t}}{P_{t}}\right)^{-\eta} C_{t}+\alpha \int_{0}^{1}\left(\frac{P_{H, t}}{\mathcal{E}_{i, t} P_{F, t}^{i}}\right)^{-\gamma}\left(\frac{P_{F, t}^{i}}{P_{t}^{i}}\right)^{-\eta} C_{t}^{i} d i\right],
\end{aligned}
$$

where the assumption of symmetric preferences across countries produces

$$
\begin{aligned}
& C_{H, t}^{i}(j)=\alpha\left(\frac{P_{H, t}(j)}{P_{H, t}}\right)^{-\varepsilon}\left(\frac{P_{H, t}}{\mathcal{E}_{i, t} P_{F, t}^{i}}\right)^{-\gamma}\left(\frac{P_{F, t}^{i}}{P_{t}^{i}}\right)^{-\eta} C_{t}^{i} \cdot \\
& \text { Substituting into } Y_{t} \equiv\left[\int_{0}^{1} Y_{t}(j)^{1-\frac{1}{\varepsilon}} d j\right]^{\frac{\varepsilon}{\varepsilon-1}} \text {, we get } \\
& Y_{t}=\left(\frac{P_{H, t}}{P_{t}}\right)^{-\eta}\left[(1-\alpha) C_{t}+\alpha \int_{0}^{1}\left(\frac{\mathcal{E}_{i, t} P_{F, t}^{i}}{P_{H, t}}\right)^{\gamma-\eta} \mathcal{Q}_{i, t}^{\eta} C_{t}^{i} d i\right] \\
& Y_{t}=S_{t}^{\alpha} C_{t}\left[(1-\alpha)+\alpha \Theta_{t}^{-1}\right] .
\end{aligned}
$$

The first-order log linear approximation is

$y_{t}=\alpha s_{t}+c_{t}-\theta_{t}$. 
Substituting this into $c_{t}=E_{t}\left\{c_{t+1}\right\}-\frac{1}{\sigma}\left(r_{t}-E_{t}\left\{\pi_{t+1}\right\}-\rho\right)$, we get

$y_{t}=E_{t}\left\{y_{t+1}\right\}-\left(r_{t}-E_{t}\left\{\pi_{t+1}\right\}-\rho\right)-\alpha\left[E_{t}\left\{s_{t+1}\right\}-s_{t}\right]+\left[E_{t}\left\{\theta_{t+1}\right\}-\theta_{t}\right]$.

\subsection{Supply Side}

At the steady state of the economy, we have

$y_{t}=a_{t}+n_{t}$

The real marginal cost is

$m c_{t}=-v+c_{t}+\varphi n_{t}+\alpha s_{t}-a_{t}$,

while the steady state real marginal cost is

$m c \equiv-\mu$.

The deviation of real marginal cost from its steady state is $\widehat{m c_{t}} \equiv m c_{t}-m c=\mu-v+c_{t}+\varphi n_{t}+\alpha s_{t}-a_{t}=\mu-v+(\varphi+1)\left(y_{t}-a_{t}\right)+\theta_{t}$.

Thus at equilibrium, the dynamic equation for inflation is

$\pi_{H, t}=\beta E_{t}\left\{\pi_{H, t+1}\right\}+\lambda \widehat{m c_{t}}=\beta E_{t}\left\{\pi_{H, t+1}\right\}+\lambda(\mu-v)+\lambda(\varphi+1) y_{t}-\lambda(\varphi+1) a_{t}+\lambda \theta_{t}$.

\subsection{Equilibrium Dynamics in Output Gap}

The natural level of output is defined to be the equilibrium output in the absence of nominal rigidities, where the deviation of real marginal cost from its steady state equals 0 , as follows:

$$
\widehat{m c_{t}}=0 \Rightarrow \bar{y}_{t}=a_{t}-\frac{1}{\varphi+1} \theta_{t}+\frac{v-\mu}{\varphi+1}
$$

The output gap is defined to be the following deviation of output from its natural level:

$x_{t} \equiv y_{t}-\bar{y}_{t}$, so that

$y_{t}=x_{t}+\bar{y}_{t}=x_{t}+\left(a_{t}-\frac{1}{\varphi+1} \theta_{t}+\frac{v-\mu}{\varphi+1}\right)$. 
We substitute that equation into the dynamics of output and inflation and also substitute $\pi_{t+1}$ into the expression of $\pi_{H, t+1}$ to acquire

$$
\begin{aligned}
& x_{t}=E_{t}\left\{x_{t+1}\right\}-\left[r_{t}-E_{t}\left\{\pi_{H, t+1}\right\}-\rho\right]+\left[E_{t}\left\{a_{t+1}\right\}-a_{t}\right]+\frac{\varphi}{\varphi+1}\left[E_{t}\left\{\theta_{t+1}\right\}-\theta_{t}\right], \\
& \pi_{H, t}=\beta E_{t}\left\{\pi_{H, t+1}\right\}+\lambda(\varphi+1) x_{t},
\end{aligned}
$$

together with the uncovered interest parity condition

$$
r_{t}-r_{t}^{*}=\left[E_{t}\left\{\theta_{t+1}\right\}-\theta_{t}\right]+\left[E_{t}\left\{s_{t+1}\right\}-s_{t}\right]+E_{t}\left\{\pi_{H, t+1}\right\}-E_{t}\left\{\pi_{t+1}^{*}\right\}
$$

The above three equations constitute the dynamics of the economy with capital controls and flexible exchange rates, but without monetary policy.

If the exchange rate is fixed, then $e_{t+1}=e_{t}$, so that

$E_{t}\left\{\pi_{H, t+1}\right\}=E_{t}\left\{\pi_{t+1}^{*}\right\}-\left[E_{t}\left\{s_{t+1}\right\}-s_{t}\right]$,

$r_{t}-r_{t}^{*}=\left[E_{t}\left\{\theta_{t+1}\right\}-\theta_{t}\right]$

In the following sections of this paper, we assume that purchasing power parity holds, so that $S_{t}=1$ and $\left[E_{t}\left\{s_{t+1}\right\}-s_{t}\right]=0$.

\section{Capital Control, Exchange Rate Regime and Monetary Policy: Four Cases}

In this section, we summarize four cases of the dynamical system, such that the exchange rate regime can be flexible or fixed and monetary policy can be current-looking or forward-looking.

\subsection{Case 1: Capital Control, Flexible Exchange Rate, Current-looking Monetary Policy}

This case is characterized by the following equations:

$$
\begin{aligned}
& x_{t}=E_{t}\left(x_{t+1}\right)-\left[r_{t}-E_{t}\left(\pi_{H, t+1}\right)-\rho\right]+\left[E_{t}\left(a_{t+1}\right)-a_{t}\right]+\frac{\varphi}{\varphi+1}\left[E_{t}\left(\theta_{t+1}\right)-\theta_{t}\right], \\
& \pi_{H, t}=\beta E_{t}\left(\pi_{H, t+1}\right)+\lambda(\varphi+1) x_{t}, \\
& r_{t}-r_{t}^{*}=\left[E_{t}\left(\theta_{t+1}\right)-\theta_{t}\right]+E_{t}\left(\pi_{H, t+1}\right)-E_{t}\left(\pi_{t+1}^{*}\right), \\
& r_{t}=a_{\pi} \pi_{H, t}+a_{x} x_{t} .
\end{aligned}
$$




\subsection{Case 2: Capital Control, Fixed Exchange Rate, Current-looking Monetary Policy}

This case is characterized by the following equations:

$x_{t}=E_{t}\left(x_{t+1}\right)-\left[r_{t}-E_{t}\left(\pi_{H, t+1}\right)-\rho\right]+\left[E_{t}\left(a_{t+1}\right)-a_{t}\right]+\frac{\varphi}{\varphi+1}\left[E_{t}\left(\theta_{t+1}\right)-\theta_{t}\right]$,

$\pi_{H, t}=\beta E_{t}\left(\pi_{H, t+1}\right)+\lambda(\varphi+1) X_{t}$,

$r_{t}-r_{t}^{*}=\left[E_{t}\left(\theta_{t+1}\right)-\theta_{t}\right]$

$r_{t}=a_{\pi} \pi_{H, t}+a_{x} X_{t}$.

\subsection{Case 3: Capital Control, Flexible Exchange Rate, Forward-looking Monetary Policy}

This case is characterized by the following equations:

$x_{t}=E_{t}\left(x_{t+1}\right)-\left[r_{t}-E_{t}\left(\pi_{H, t+1}\right)-\rho\right]+\left[E_{t}\left(a_{t+1}\right)-a_{t}\right]+\frac{\varphi}{\varphi+1}\left[E_{t}\left(\theta_{t+1}\right)-\theta_{t}\right]$,

$\pi_{H, t}=\beta E_{t}\left(\pi_{H, t+1}\right)+\lambda(\varphi+1) X_{t}$,

$r_{t}-r_{t}^{*}=\left[E_{t}\left(\theta_{t+1}\right)-\theta_{t}\right]+E_{t}\left(\pi_{H, t+1}\right)-E_{t}\left(\pi_{t+1}^{*}\right)$,

$r_{t}=a_{\pi} E_{t}\left(\pi_{H, t+1}\right)+a_{x} E_{t}\left(x_{t+1}\right)$.

\subsection{Case 4: Capital Control, Fixed Exchange Rate, Forward-looking Monetary Policy}

This case is characterized by the following equations:

$x_{t}=E_{t}\left(x_{t+1}\right)-\left[r_{t}-E_{t}\left(\pi_{H, t+1}\right)-\rho\right]+\left[E_{t}\left(a_{t+1}\right)-a_{t}\right]+\frac{\varphi}{\varphi+1}\left[E_{t}\left(\theta_{t+1}\right)-\theta_{t}\right]$,

$\pi_{H, t}=\beta E_{t}\left(\pi_{H, t+1}\right)+\lambda(\varphi+1) x_{t}$,

$r_{t}-r_{t}^{*}=\left[E_{t}\left(\theta_{t+1}\right)-\theta_{t}\right]$

$r_{t}=a_{\pi} E_{t}\left(\pi_{H, t+1}\right)+a_{x} E_{t}\left(x_{t+1}\right)$.

The four cases have the same IS curve and Phillips curve. The differences lie in the uncovered interest parity conditions between flexible exchange rates and fixed exchange rates, and in the interest rate feedback rule between current-looking monetary policy and forward-looking monetary policy. It should be observed that our uncovered interest parity (UIP) condition is somewhat unusual. The usual UIP condition mainly describes the relationship between exchange rates and nominal interest rates. In our UIP condition, the nominal interest rate depends upon capital controls and upon how large the expectation of future domestic inflation will deviate from world inflation. 
If the capital flow is free, so that $\tau_{t+1}=\sigma\left(\theta_{t+1}-\theta_{t}\right)=0$, then under fixed exchange rates, the domestic nominal interest rate should equal the world nominal interest rate. As a result, the monetary authority loses its autonomy, in accordance with Mundell's trilemma. Second, under flexible exchange rates, the expectation of future world inflation plays a role in the dynamical system. Even though the domestic government stops targeting exchange rates and allows the exchange rate to float freely, the system is still influenced by expectations of the world inflation.

We also investigate how expectations about future domestic inflation and output gap change the results of our analysis, compared with current-looking monetary policy with the central bank setting the nominal interest rate.

\section{Indeterminacy}

In this section we investigate the indeterminacy conditions for the four cases of policy combinations. We follow the method for linear rational expectations models by Lubik and Schorfheide (2003), Lubik and Schorfheide (2004), Lubik and Marzo (2007), Sims (2002), Farmer et al. (2015), Beyer and Farmer (2004).

In Lubik and Schorfheide (2003), the indeterminacy condition is provided as follows. First, the system can be written as

$\Gamma_{0} \mathbf{X}_{t}=\Gamma_{1} \mathbf{X}_{t-1}+\Psi \boldsymbol{\varepsilon}_{t}+\boldsymbol{\Pi} \boldsymbol{\eta}_{t}$

where $\mathbf{X}_{t}$ is the $n \times 1$ vector of endogenous variables and their expectations, while $\boldsymbol{\varepsilon}_{t}$ is the $l \times 1$ vector of exogenous variables, and $\boldsymbol{\eta}_{t}$ is the $k \times 1$ vector of non-fundamental forecasting errors. Those forecast errors represent beliefs and permit self-fulfilling equilibria.

The reduced form of the above system is

$\mathbf{X}_{t}=\boldsymbol{\Gamma}_{0}^{-1} \boldsymbol{\Gamma}_{1} \mathbf{X}_{t-1}+\boldsymbol{\Gamma}_{0}^{-1} \boldsymbol{\Psi} \boldsymbol{\varepsilon}_{t}+\boldsymbol{\Gamma}_{0}^{-1} \boldsymbol{\Pi} \boldsymbol{\eta}_{t}$

Applying generalized Schur decomposition (also called QZ decomposition) and letting $\mathbf{w}_{t}=\mathbf{Z}^{\prime} \mathbf{X}_{t}$, the equation above can be written as

$$
\left[\begin{array}{cc}
\boldsymbol{\Lambda}_{11} & \boldsymbol{\Lambda}_{12} \\
0 & \boldsymbol{\Lambda}_{22}
\end{array}\right]\left[\begin{array}{c}
\mathbf{w}_{1, t} \\
\mathbf{w}_{2, t}
\end{array}\right]=\left[\begin{array}{cc}
\boldsymbol{\Omega}_{11} & \boldsymbol{\Omega}_{12} \\
0 & \boldsymbol{\Omega}_{22}
\end{array}\right]\left[\begin{array}{c}
\mathbf{w}_{1, t-1} \\
\mathbf{w}_{2, t-1}
\end{array}\right]+\left[\begin{array}{l}
\mathbf{Q}_{1 .} \\
\mathbf{Q}_{2 .}
\end{array}\right]\left(\boldsymbol{\Psi} \boldsymbol{\varepsilon}_{t}+\boldsymbol{\Pi} \boldsymbol{\eta}_{t}\right)
$$

It is assumed that the following $m \times 1$ vector, $\mathbf{w}_{2, t}$, is purely explosive, where $0 \leq m \leq n$ : 
$\mathbf{w}_{2, t}=\Lambda_{22}^{-1} \mathbf{\Omega}_{22} \mathbf{w}_{2, t-1}+\Lambda_{22}^{-1} \mathbf{Q}_{2 .}\left(\Psi \boldsymbol{\varepsilon}_{t}+\Pi \boldsymbol{\eta}_{t}\right)$

A non-explosive solution of the linear rational expectation model for $\mathbf{X}_{t}$ exists, if $\mathbf{w}_{2,0}=\mathbf{0}$ and $\mathbf{Q}_{2 .} \Psi \boldsymbol{\varepsilon}_{t}+\mathbf{Q}_{2 .} \Pi \eta_{t}=0$

By singular value decomposition of $\mathbf{Q}_{2} \boldsymbol{\Pi}$, we find

$\mathbf{Q}_{2 .} \boldsymbol{\Pi}=\mathbf{U D V} \mathbf{V}^{\prime}=\left[\begin{array}{ll}\mathbf{U}_{.1} & \mathbf{U}_{.2}\end{array}\right]\left[\begin{array}{cc}\mathbf{D}_{11} & \mathbf{0} \\ \mathbf{0} & \mathbf{0}\end{array}\right]\left[\begin{array}{c}\mathbf{V}_{.1}^{\prime} \\ \mathbf{V}_{.2}^{\prime}\end{array}\right]=\mathbf{U}_{.1} \mathbf{D}_{11} \mathbf{V}_{.1}^{\prime}$

The $m$ explosive components of $\mathbf{X}_{t}$ generate $r \leq m$ restrictions for the expectation errors. The stability condition can be rewritten as

$\mathbf{U}_{.1} \mathbf{D}_{11}\left(\mathbf{V}_{.1}^{\prime} \lambda \boldsymbol{\varepsilon}_{t}+\mathbf{V}_{.1}^{\prime} \boldsymbol{\eta}_{t}\right)=0$

Let $\boldsymbol{\eta}_{t}=\mathbf{A}_{1} \boldsymbol{\varepsilon}_{t}+\mathbf{A}_{2} \zeta_{t}$, where $\zeta_{t}$ is a $p \times 1$ vector of sunspot shocks. The solution for the forecast errors is

$\boldsymbol{\eta}_{t}=\left(-\mathbf{V}_{.1} \mathbf{D}_{11}^{-1} \mathbf{U}_{.1}^{\prime} \mathbf{Q}_{2 .} \mathbf{\Psi}+\mathbf{V}_{.2} \mathbf{M}_{1}\right) \boldsymbol{\varepsilon}_{t}+\mathbf{V}_{.2} \mathbf{M}_{2} \zeta_{t}$

When the dimension of the vector of forecast errors, $k$, equals the number of stability restrictions, $r$, the linear rational expectations model has a unique solution. When $k>r$, there is indeterminacy (multiple stable solutions), and $k-r$ is the degree of indeterminacy.

\subsection{Case 1}

Under capital control, flexible exchange rates, and current-looking monetary policy, the system can be rewritten as

$$
\begin{aligned}
& E_{t}\left(x_{t+1}\right)=\left(1+\frac{a_{x}}{\varphi+1}+\frac{\lambda}{\beta}\right) x_{t}-\frac{\left(1-a_{\pi} \beta\right)}{\beta(\varphi+1)} \pi_{H, t}-\left[E_{t}\left(a_{t+1}\right)-a_{t}\right]+\frac{\varphi}{\varphi+1} r_{t}^{*}-\frac{\varphi}{\varphi+1} E_{t}\left(\pi_{t+1}^{*}\right)-\rho, \\
& E_{t}\left(\pi_{H, t+1}\right)=\frac{1}{\beta} \pi_{H, t}-\frac{\lambda(\varphi+1)}{\beta} x_{t} .
\end{aligned}
$$

The two-dimensional subsystem for the conditional expectations, $\xi_{t}=\left[\begin{array}{ll}\xi_{t}^{x} & \xi_{t}^{\pi_{H}}\end{array}\right]^{\prime}$, where $\xi_{t}^{x}=E_{t}\left(x_{t+1}\right)$ and $\xi_{t}^{\pi_{H}}=E_{t}\left(\pi_{H, t+1}\right)$ can be written as 
$\xi_{t}=\Gamma_{1}^{*} \boldsymbol{\xi}_{t-1}+\boldsymbol{\Psi}^{*} \boldsymbol{\varepsilon}_{t}+\boldsymbol{\Pi}^{*} \boldsymbol{\eta}_{t}$

The eigenvalues for $\boldsymbol{\Gamma}_{1}^{*}$ are

$\mu_{1}, \mu_{2}=\frac{A+\frac{1}{\beta} \pm \sqrt{\left(A+\frac{1}{\beta}\right)^{2}-\frac{4(A-E B)}{\beta}}}{2}$,

where

$A=1+\frac{a_{x}}{\varphi+1}+\frac{\lambda}{\beta}$

$B=\frac{\left(1-a_{\pi} \beta\right)}{\beta(\varphi+1)}$,

$E=\lambda(\varphi+1)$.

Since the number of non-fundamental errors $k=2$, when $r=m=1$, there will be one degree of indeterminacy. This requires that only one of the roots, $\mu_{1}$ and $\mu_{2}$, be unstable, resulting in this conclusion.

Proposition 1. Under capital control, flexible exchange rate and current-looking monetary policy, there exists one degree of indeterminacy, when $\lambda(\varphi+1)\left(1-a_{\pi}\right)+a_{x}(\beta-1)>0$.

\subsection{Case 2}

Under capital control, fixed exchange rates, and current-looking monetary policy, the system can be rewritten as

$$
\begin{aligned}
& E_{t}\left(x_{t+1}\right)=\left(1+\frac{a_{x}}{\varphi+1}+\frac{\varphi+1}{\beta}\right) x_{t}-\left(\frac{1}{\beta}-\frac{a_{\pi}}{\varphi+1}\right) \pi_{H, t}-\left[E_{t}\left(a_{t+1}\right)-a_{t}\right]+\frac{\varphi}{\varphi+1} r_{t}^{*}-\rho, \\
& E_{t}\left(\pi_{H, t+1}\right)=\frac{1}{\beta} \pi_{H, t}-\frac{\lambda(\varphi+1)}{\beta} x_{t} .
\end{aligned}
$$

The eigenvalues of matrix $\Gamma_{1}^{*}$ are

$\mu_{1}, \mu_{2}=\frac{A+\frac{1}{\beta} \pm \sqrt{\left(A+\frac{1}{\beta}\right)^{2}-\frac{4(A-E B)}{\beta}}}{2}$,

where 


$$
\begin{aligned}
& A=1+\frac{a_{x}}{\varphi+1}+\frac{\varphi+1}{\beta}, \\
& B=\frac{1}{\beta}-\frac{a_{\pi}}{\varphi+1}, \\
& E=\lambda(\varphi+1) .
\end{aligned}
$$

This result follows.

Proposition 2. Under capital control, fixed exchange rates, and current-looking monetary policy, there exists one degree of indeterminacy, when $(\varphi+1)^{2}(\beta+\lambda-1)+\beta\left[a_{x}(\beta-1)-\lambda a_{\pi}\right]>0$.

\subsection{Case 3}

Under capital control, flexible exchange rates, and forward-looking monetary policy, the system can be rewritten as

$$
\begin{aligned}
& \left(1-\frac{a_{x}}{\varphi+1}\right) E_{t}\left(x_{t+1}\right)=\left[1-\frac{\lambda\left(a_{\pi}-1\right)}{\beta}\right] x_{t}-\frac{\left(1-a_{\pi}\right)}{\beta(\varphi+1)} \pi_{H, t}-\left[E_{t}\left(a_{t+1}\right)-a_{t}\right]+\frac{\varphi}{\varphi+1} r_{t}^{*}-\frac{\varphi}{\varphi+1} E_{t}\left(\pi_{t+1}^{*}\right)-\rho, \\
& E_{t}\left(\pi_{H, t+1}\right)=\frac{1}{\beta} \pi_{H, t}-\frac{\lambda(\varphi+1)}{\beta} x_{t} .
\end{aligned}
$$

The eigenvalues of matrix $\Gamma_{1}^{*}$ are

$\mu_{1}, \mu_{2}=\frac{\frac{A}{F}+\frac{1}{\beta} \pm \sqrt{\left(\frac{A}{F}+\frac{1}{\beta}\right)^{2}-\frac{4(A-E B)}{F \beta}}}{2}$,

where

$$
\begin{aligned}
& A=1-\frac{\lambda\left(a_{\pi}-1\right)}{\beta}, \\
& B=\frac{1-a_{\pi}}{\beta(\varphi+1)}, \\
& E=\lambda(\varphi+1), \\
& F=1-\frac{a_{x}}{\varphi+1} .
\end{aligned}
$$

This result follows. 
Proposition 3. Under capital control, flexible exchange rates, and forward-looking monetary policy, there exists one degree of indeterminacy, when

$$
\left\{\begin{array} { c } 
{ a _ { x } < \varphi + 1 } \\
{ \lambda ( \varphi + 1 ) ( 1 - a _ { \pi } ) + a _ { x } ( \beta - 1 ) > 0 }
\end{array} \text { or } \left\{\begin{array}{c}
a_{x}>\varphi+1 \\
\lambda(\varphi+1)\left(1-a_{\pi}\right)+a_{x}(\beta-1)<0
\end{array} .\right.\right.
$$

\subsection{Case 4}

Under capital control, fixed exchange rates, and forward-looking monetary policy, the system can be rewritten as

$$
\begin{aligned}
& \left(1-\frac{a_{x}}{\varphi+1}\right) E_{t}\left(x_{t+1}\right)=\left[1+\frac{\lambda\left(\varphi+1-a_{\pi}\right)}{\beta}\right] x_{t}-\left[\frac{1}{\beta}-\frac{a_{\pi}}{\beta(\varphi+1)}\right] \pi_{H, t}-\left[E_{t}\left(a_{t+1}\right)-a_{t}\right]+\frac{\varphi}{\varphi+1} r_{t}^{*}-\rho, \\
& E_{t}\left(\pi_{H, t+1}\right)=\frac{1}{\beta} \pi_{H, t}-\frac{\lambda(\varphi+1)}{\beta} x_{t} .
\end{aligned}
$$

The eigenvalues of matrix $\Gamma_{1}^{*}$ are

$\mu_{1}, \mu_{2}=\frac{\frac{A}{F}+\frac{1}{\beta} \pm \sqrt{\left(\frac{A}{F}+\frac{1}{\beta}\right)^{2}-\frac{4(A-E B)}{F \beta}}}{2}$,

where

$A=1+\frac{\lambda\left(\varphi+1-a_{\pi}\right)}{\beta}$,

$B=\frac{1}{\beta}-\frac{a_{\pi}}{\beta(\varphi+1)}$

$E=\lambda(\varphi+1)$,

$F=1-\frac{a_{x}}{\varphi+1}$.

This result follows.

Proposition 4. Under capital control, fixed exchange rates, and forward-looking monetary policy, there exists one degree of indeterminacy, when

$$
\left\{\begin{array} { c } 
{ a _ { x } < \varphi + 1 } \\
{ \lambda ( \varphi + 1 ) ( \varphi + 1 - a _ { \pi } ) + a _ { x } ( \beta - 1 ) > 0 }
\end{array} \text { or } \left\{\begin{array}{c}
a_{x}>\varphi+1 \\
\lambda(\varphi+1)\left(\varphi+1-a_{\pi}\right)+a_{x}(\beta-1)<0
\end{array}\right.\right. \text {. }
$$


We summarize the indeterminacy conditions for the four cases in the table below.

Table 1: Indeterminacy Conditions

\begin{tabular}{|c|c|}
\hline Policies & Indeterminacy conditions \\
\hline $\begin{array}{l}\text { Capital control, Flexible exchange rates, } \\
\text { Current-looking monetary policy }\end{array}$ & $\lambda(\varphi+1)\left(1-a_{\pi}\right)+a_{x}(\beta-1)>0$ \\
\hline $\begin{array}{l}\text { Capital control, Fixed exchange rates, } \\
\text { Current-looking monetary policy }\end{array}$ & $(\varphi+1)^{2}(\beta+\lambda-1)+\beta\left[a_{x}(\beta-1)-\lambda a_{\pi}\right]>0$ \\
\hline $\begin{array}{l}\text { Capital control, Flexible exchange rates, } \\
\text { Forward-looking monetary policy }\end{array}$ & $\begin{array}{c}\left\{\begin{array}{c}a_{x}<\varphi+1 \\
\lambda(\varphi+1)\left(1-a_{\pi}\right)+a_{x}(\beta-1)>0\end{array}\right. \\
\text { or } \\
\left\{\begin{array}{c}a_{x}>\varphi+1 \\
\lambda(\varphi+1)\left(1-a_{\pi}\right)+a_{x}(\beta-1)<0\end{array}\right.\end{array}$ \\
\hline $\begin{array}{l}\text { Capital control, Fixed exchange rates, } \\
\text { Forward-looking monetary policy }\end{array}$ & $\begin{array}{c}\left\{\begin{array}{c}a_{x}<\varphi+1 \\
\lambda(\varphi+1)\left(\varphi+1-a_{\pi}\right)+a_{x}(\beta-1)>0\end{array}\right. \\
\text { or } \\
\lambda\left(\begin{array}{c}a_{x}>\varphi+1 \\
\lambda(1)\left(\varphi+1-a_{\pi}\right)+a_{x}(\beta-1)<0\end{array}\right.\end{array}$ \\
\hline
\end{tabular}

\section{Bifurcation}

In this section, we investigate the existence of bifurcation in the system under the four policy cases. With Hopf bifurcation, the economy can converge to a stable limit cycle or diverge from an unstable limit cycle. We use the following theorem from Gandolfo (2010) to determine conditions for the existence of Hopf bifurcation.

Theorem. Consider the system, $y_{t+1}=\varphi\left(y_{t}, \alpha\right)$. Suppose that for each $\alpha$ in the relevant interval, the system has a smooth family of equilibrium points, $y_{e}=y_{e}(\alpha)$, at which the eigenvalues are complex conjugates, $\lambda_{1,2}=\theta(\alpha) \pm i \omega(\alpha)$. If there is a critical value, $\alpha_{0}$, of the parameter $\alpha$ such that

(1) the eigenvalues' modulus becomes unity at $\alpha_{0}$, but the eigenvalues are not roots of unity (from the first up to the fourth), namely 


$$
\begin{aligned}
& \left|\lambda_{1,2}\left(\alpha_{0}\right)\right|=+\sqrt{\theta^{2}+\omega^{2}}=1, \lambda_{1,2}^{j}\left(\alpha_{0}\right) \neq 1 \text { for } \mathrm{j}=1,2,3,4, \\
& \text { (2) }\left.\frac{d\left|\lambda_{1,2}(\alpha)\right|}{d \alpha}\right|_{\alpha=\alpha_{0}} \neq 0,
\end{aligned}
$$

then there is an invariant closed curve bifurcating from $\alpha_{0}$.

\subsection{Case 1}

We rewrite the system in $2 \times 2$ form as

$\left[\begin{array}{c}E_{t}\left(x_{t+1}\right) \\ E_{t}\left(\pi_{H, t+1}\right)\end{array}\right]=\left[\begin{array}{cc}A & -B \\ -\frac{E}{\beta} & \frac{1}{\beta}\end{array}\right]\left[\begin{array}{c}x_{t} \\ \pi_{H, t}\end{array}\right]+\mathbf{\Psi Z}_{t}+\mathbf{C}$,

where $A, B, E$, and $\mathbf{Z}_{t}$ are defined the same as in Case 1 for indeterminacy. The characteristic equation is

$\mu^{2}-\left(A+\frac{1}{\beta}\right) \mu+\frac{A-E B}{\beta}=0$.

For bifurcation to exist, the following conditions must be satisfied:

$D=\left(A+\frac{1}{\beta}\right)^{2}-4 \frac{A-E B}{\beta}<0$,

$\left|\mu_{1,2}\right|=\sqrt{\theta^{2}+\omega^{2}}=\sqrt{\mu_{1} \mu_{2}}=\sqrt{\frac{A-E B}{\beta}}=1$.

This result follows.

Proposition 5. Under capital control, flexible exchange rates, and current-looking monetary policy, there would exist Hopf bifurcation, if $\left[(\varphi+1)(\beta+\lambda-1)+a_{x} \beta\right]^{2}+4 \lambda(\varphi+1)^{2}\left(1-a_{\pi} \beta\right)<0$ and $(\varphi+1)\left(1-\beta+\lambda a_{\pi}\right)+a_{x}=0$. However, according to the meaning of the parameters, the second equation cannot be satisfied.

\subsection{Case 2}


We again rewrite the system in $2 \times 2$ form as equations (34), but with $A, B, E$, and $\mathbf{Z}_{t}$ defined as in Case 2 for indeterminacy. The characteristic equation and the bifurcation condition equations are the same as in Case 1 , but with the different settings of $A, B, E$, and $\mathbf{Z}_{t}$.

This result follows.

Proposition 6. Under capital control, fixed exchange rates, and current-looking monetary policy, there exists Hopf bifurcation, when $\left[(\varphi+1)(\beta+\varphi)+a_{x} \beta\right]^{2}+4 \lambda(\varphi+1)^{2}\left(\varphi+1-a_{\pi} \beta\right)<0$ and $(1-\lambda)(\varphi+1)^{2}+\beta(1-\beta)(\varphi+1)+\lambda a_{\pi} \beta(\varphi+1)+a_{x} \beta=0$. Since $\lambda=\frac{(1-\beta \theta)(1-\theta)}{\theta}$ with $0<\beta<1$, and $0<\theta<1$, it follows that $\lambda$ goes to $+\infty$, when $\theta$ approaches 0 . In this case, it is possible for the second equality to hold.

\subsection{Case 3}

We again rewrite the system in $2 \times 2$ form as equations (34), but with $A, B, E$, and $\mathbf{Z}_{t}$ defined as in Case 3 for indeterminacy. The characteristic equation is

$\mu^{2}-\left(\frac{A}{F}+\frac{1}{\beta}\right) \mu+\frac{A-E B}{F \beta}=0$.

For bifurcation to exist, the following conditions must be satisfied.

$D=\left(\frac{A}{F}+\frac{1}{\beta}\right)^{2}-4 \frac{A-E B}{F \beta}<0$,

$\left|\mu_{1,2}\right|=\sqrt{\theta^{2}+\omega^{2}}=\sqrt{\mu_{1} \mu_{2}}=\sqrt{\frac{A-E B}{F \beta}}=1$.

This result follows.

Proposition 7. Under capital control, flexible exchange rates, and forward-looking monetary policy, there could exist Hopf bifurcation, if

$\left[(\beta-1)(\varphi+1)-\lambda\left(a_{\pi}-1\right)(\varphi+1)+a_{x}\right]^{2}+4 \lambda(\varphi+1)\left(1-a_{\pi}\right)\left(\varphi+1-a_{x}\right)<0$ and

$(1-\beta)(\varphi+1)+a_{x} \beta=0$. However, according to the economic meaning of the parameters, the second equation cannot be satisfied with parameter values within their feasible range.

\subsection{Case 4}


We again rewrite the system in $2 \times 2$ form as equations (34), but with $A, B, E$, and $\mathbf{Z}_{t}$ defined the same as in Case 4 for indeterminacy. The characteristic equation and the bifurcation condition equations are the same as in Case 3, but with different settings of $A, B, E$, and $\mathbf{Z}_{t}$.

This result follows.

Proposition 8. Under capital control, fixed exchange rates, and forward-looking monetary policy, there could exist Hopf bifurcation, if

$\left[\left(\beta+\lambda\left(\varphi+1-a_{\pi}\right)-1\right)(\varphi+1)+a_{x}\right]^{2}+4 \lambda(\varphi+1)\left(\varphi+1-a_{\pi}\right)\left(\varphi+1-a_{x}\right)<0$ and

$(1-\beta)(\varphi+1)+a_{x} \beta=0$. However, according to the meaning of the parameters, the second equation cannot be satisfied.

We summarize the conditions for Hopf bifurcation to exist in the four cases with the parameters within their feasible range.

Table 2: Bifurcation Conditions

\begin{tabular}{|l|l|l|}
\hline Policies & \multicolumn{1}{|c|}{ Bifurcation conditions } & Possible \\
\hline Case 1 & $\begin{array}{l}{\left[(\varphi+1)(\beta+\lambda-1)+a_{x} \beta\right]^{2}+4 \lambda(\varphi+1)^{2}\left(1-a_{\pi} \beta\right)<0} \\
(\varphi+1)\left(1-\beta+\lambda a_{\pi}\right)+a_{x}=0\end{array}$ & No \\
\hline Case 2 & $\begin{array}{l}{\left[(\varphi+1)(\beta+\varphi)+a_{x} \beta\right]^{2}+4 \lambda(\varphi+1)^{2}\left(\varphi+1-a_{\pi} \beta\right)<0} \\
(1-\lambda)(\varphi+1)^{2}+\beta(1-\beta)(\varphi+1)+\lambda a_{\pi} \beta(\varphi+1)+a_{x} \beta=0\end{array}$ & Yes \\
\hline Case 3 & $\begin{array}{l}{\left[(\beta-1)(\varphi+1)-\lambda\left(a_{\pi}-1\right)(\varphi+1)+a_{x}\right]^{2}+4 \lambda(\varphi+1)\left(1-a_{\pi}\right)\left(\varphi+1-a_{x}\right)<0} \\
(1-\beta)(\varphi+1)+a_{x} \beta=0\end{array}$ & No \\
\hline Case 4 & $\begin{array}{l}{\left[\left(\beta+\lambda\left(\varphi+1-a_{\pi}\right)-1\right)(\varphi+1)+a_{x}\right]^{2}+4 \lambda(\varphi+1)\left(\varphi+1-a_{\pi}\right)\left(\varphi+1-a_{x}\right)<0} \\
(1-\beta)(\varphi+1)+a_{x} \beta=0\end{array}$ & No \\
\hline
\end{tabular}

\section{Economic Implication}

Case 1: Indeterminacy is determined by how $\lambda$ and $a_{\pi}$ are coordinated with $a_{x}$. To assure that the summation is larger than zero, $a_{\pi}$ must be between zero and one. If $\lambda$ is large, then $a_{x}$ can be large or small, so long as $\lambda$ is sufficiently larger than $a_{x}$. If $\lambda$ is small, $a_{x}$ can only be small to make the summation larger than zero. 
Case 2: To assure the summation is larger than zero, we must have $\beta+\lambda-1>0$. In addition, $a_{\pi}$ must not be too large, since $\lambda$ appears both in the front part $\beta+\lambda-1$ and the back part $\lambda a_{\pi}$. If $a_{\pi}$ is too large, the negative part in the summation will outweigh the positive part and make the summation negative. Finally, $a_{x}$ cannot be too large. Regarding bifurcation in Case 2, the condition will be satisfied when $\lambda$ is larger than one, with relevant coordination of $a_{x}$ and $a_{\pi}$

Case 3: Compared with Case 1, Case 3 must consider $a_{x}$ first. When $a_{x}$ is small, the summation is larger than zero, only if $a_{\pi}$ is between zero and one. In this situation, it does not matter whether $\lambda$ is large or small. When $a_{x}$ is large, there are two possibilities for indeterminacy to appear. One is that $a_{\pi}$ is also large, regardless of whether $\lambda$ is large or small. The other is when $a_{\pi}$ is small, in which case $\lambda$ must not be larger than $a_{x}$.

Case 4: This case is similar to Case 3, but more ambiguous, because the condition also depends on $\varphi$ in a subtle way. For example, we must consider $\varphi+1-a_{\pi}$ instead of $1-a_{\pi}$.

We summarize the economic implications for these several conditions in the table below. We find that expectations in the interest feedback rule create possibilities for indeterminacy. For forwardlooking monetary policy, both passive and positive feedback on inflation and output gap may lead to indeterminacy, regardless of stickiness of prices. Compared with flexible exchange rates, the conditions with fixed exchange rates is more complicated. Not only can bifurcation exist under fixed exchange rates, but also indeterminacy, depending upon the labor elasticity of substitution. Policy caution is needed under fixed exchange rates with capital controls, because price setting and labor behavior must be taken into consideration as well.

Our results expand upon prior results on the relationship between monetary policy and indeterminacy. Under capital controls, not only feedback on inflation can lead to indeterminacy. Indeterminacy conditions can also depend upon feedback on both inflation and output gap. 
Table 3: Summary Results

\begin{tabular}{|c|c|c|}
\hline Policies & Indeterminacy & Bifurcation \\
\hline $\begin{array}{l}\text { Capital control, } \\
\text { Flexible exchange rates, } \\
\text { Current-looking } \\
\text { monetary policy }\end{array}$ & $\begin{array}{l}\text { (1) Prices flexible, passive feedback on } \\
\text { inflation. } \\
\text { or } \\
\text { (2) Prices sticky, passive feedback both } \\
\text { on inflation and output gap. }\end{array}$ & \\
\hline $\begin{array}{l}\text { Capital control, } \\
\text { Fixed exchange rates, } \\
\text { Current-looking } \\
\text { monetary policy }\end{array}$ & $\begin{array}{l}\text { Passive feedback both on inflation and } \\
\text { output gap and sticky prices }\end{array}$ & Prices flexible \\
\hline $\begin{array}{l}\text { Capital control, } \\
\text { Flexible exchange rates, } \\
\text { Forward-looking } \\
\text { monetary policy }\end{array}$ & $\begin{array}{l}\text { (1) Passive/positive feedback both on } \\
\text { inflation and output gap. } \\
\text { or } \\
\text { (2) Positive feedback on output gap and } \\
\text { passive feedback on inflation. }\end{array}$ & \\
\hline $\begin{array}{l}\text { Capital control, } \\
\text { Fixed exchange rate, } \\
\text { Forward-looking } \\
\text { monetary policy }\end{array}$ & $\begin{array}{l}\text { (1) Passive/positive feedback both on } \\
\text { inflation and output gap } \\
\text { (with condition on labor elasticity of } \\
\text { substitution). } \\
\text { or } \\
\text { (2) Positive feedback on output gap and } \\
\text { passive feedback on inflation } \\
\text { (with condition on labor elasticity of } \\
\text { substitution). }\end{array}$ & \\
\hline
\end{tabular}

\section{Testing for Indeterminacy}

In this section, we test indeterminacy using Bayesian likelihood estimation, following Lubik and Schorfheide (2004). We compute the posterior probability of the determinate and the indeterminate regions of the parameter space. Then we estimate the parameters' posterior means and 90-percent probability intervals. We also study impulse responses of the fundamental and sunspot shocks. We use GAUSS for computations. 


\subsection{Model Used for Testing Indeterminacy}

\subsubsection{Case 1}

In Case 1, the model is:

$$
\begin{aligned}
& x_{t}=E_{t-1}\left[x_{t}\right]+\eta_{1, t}, \\
& \pi_{H, t}=E_{t-1}\left[\pi_{H, t}\right]+\eta_{2, t}, \\
& x_{t}=E_{t}\left[x_{t+1}\right]-\frac{1}{\varphi+1} r_{t}+\frac{1}{\varphi+1} E_{t}\left[\pi_{H, t+1}\right]+z_{t}-\frac{\varphi}{\varphi+1} r_{t}^{*}+\frac{\varphi}{\varphi+1} \pi_{t+1}^{*}+\rho, \\
& \pi_{H, t}=\beta E_{t}\left[\pi_{H, t+1}\right]+\lambda(\varphi+1) x_{t}, \\
& r_{t}=a_{\pi} \pi_{H, t}+a_{x} x_{t}+\varepsilon_{r, t}, \\
& z_{t}=\rho_{z} z_{t-1}+\varepsilon_{z, t}, \\
& r_{t}^{*}=\rho_{R} r_{t-1}^{*}+\varepsilon_{R, t}, \\
& \pi_{t}^{*}=\rho_{\pi} \pi_{t-1}^{*}+\varepsilon_{\pi, t},
\end{aligned}
$$

which can be written as

$\boldsymbol{\Gamma}_{0}(\boldsymbol{\theta}) \mathbf{s}_{t}=\boldsymbol{\Gamma}_{1}(\boldsymbol{\theta}) \mathbf{s}_{t-1}+\boldsymbol{\Psi}(\boldsymbol{\theta}) \boldsymbol{\varepsilon}_{t}+\boldsymbol{\Pi}(\boldsymbol{\theta}) \boldsymbol{\eta}_{t}$,

$\boldsymbol{\eta}_{t}=\mathbf{A}_{1} \boldsymbol{\varepsilon}_{t}+\mathbf{A}_{2} \zeta_{t}$,

with

$$
\begin{aligned}
& \mathbf{s}_{t}=\left[x_{t}, \pi_{H, t}, r_{t}, E_{t}\left[x_{t+1}\right], E_{t}\left[\pi_{H, t+1}\right], z_{t}, r_{t}^{*}, \pi_{t}^{*}\right]^{\prime}, \\
& \boldsymbol{\varepsilon}_{t}=\left[\varepsilon_{r, t}, \varepsilon_{z, t}, \varepsilon_{R, t}, \varepsilon_{\pi, t}\right]^{\prime}, \\
& \boldsymbol{\eta}_{t}=\left[\left(x_{t}-E_{t-1}\left[x_{t}\right]\right),\left(\pi_{H, t}-E_{t-1}\left[\pi_{H, t}\right]\right)\right]^{\prime} .
\end{aligned}
$$

\subsubsection{Case 2}

In Case 2, the model is: 


$$
\begin{aligned}
& x_{t}=E_{t-1}\left[x_{t}\right]+\eta_{1, t}, \\
& \pi_{H, t}=E_{t-1}\left[\pi_{H, t}\right]+\eta_{2, t}, \\
& x_{t}=E_{t}\left[x_{t+1}\right]-\frac{1}{\varphi+1} r_{t}+E_{t}\left[\pi_{H, t+1}\right]+z_{t}-\frac{\varphi}{\varphi+1} r_{t}^{*}+\rho, \\
& \pi_{H, t}=\beta E_{t}\left[\pi_{H, t+1}\right]+\lambda(\varphi+1) x_{t}, \\
& r_{t}=a_{\pi} \pi_{H, t}+a_{x} x_{t}+\varepsilon_{r, t}, \\
& z_{t}=\rho_{z} z_{t-1}+\varepsilon_{z, t}, \\
& r_{t}^{*}=\rho_{R} r_{t-1}^{*}+\varepsilon_{R, t},
\end{aligned}
$$

which can be written as (35) with

$$
\begin{aligned}
& \mathbf{s}_{t}=\left[x_{t}, \pi_{H, t}, r_{t}, E_{t}\left[x_{t+1}\right], E_{t}\left[\pi_{H, t+1}\right], z_{t}, r_{t}^{*}\right]^{\prime}, \\
& \boldsymbol{\varepsilon}_{t}=\left[\varepsilon_{r, t}, \varepsilon_{z, t}, \varepsilon_{R, t}\right]^{\prime}, \\
& \boldsymbol{\eta}_{t}=\left[\left(x_{t}-E_{t-1}\left[x_{t}\right]\right),\left(\pi_{H, t}-E_{t-1}\left[\pi_{H, t}\right]\right)\right]^{\prime} .
\end{aligned}
$$

\subsubsection{Case 3}

In Case 3, the model is:

$$
\begin{aligned}
& x_{t}=E_{t-1}\left[x_{t}\right]+\eta_{1, t}, \\
& \pi_{H, t}=E_{t-1}\left[\pi_{H, t}\right]+\eta_{2, t}, \\
& x_{t}=E_{t}\left[x_{t+1}\right]-\frac{1}{\varphi+1} r_{t}+\frac{1}{\varphi+1} E_{t}\left[\pi_{H, t+1}\right]+z_{t}-\frac{\varphi}{\varphi+1} r_{t}^{*}+\frac{\varphi}{\varphi+1} \pi_{t+1}^{*}+\rho, \\
& \pi_{H, t}=\beta E_{t}\left[\pi_{H, t+1}\right]+\lambda(\varphi+1) x_{t}, \\
& r_{t}=a_{\pi} E_{t}\left[\pi_{H, t+1}\right]+a_{x} E_{t}\left[x_{t+1}\right]+\varepsilon_{r, t}, \\
& z_{t}=\rho_{z} z_{t-1}+\varepsilon_{z, t}, \\
& r_{t}^{*}=\rho_{R} r_{t-1}^{*}+\varepsilon_{R, t}, \\
& \pi_{t}^{*}=\rho_{\pi} \pi_{t-1}^{*}+\varepsilon_{\pi, t},
\end{aligned}
$$

which can be written as (35) with 


$$
\begin{aligned}
& \mathbf{s}_{t}=\left[x_{t}, \pi_{H, t}, r_{t}, E_{t}\left[x_{t+1}\right], E_{t}\left[\pi_{H, t+1}\right], z_{t}, r_{t}^{*}, \pi_{t}^{*}\right]^{\prime}, \\
& \boldsymbol{\varepsilon}_{t}=\left[\varepsilon_{r, t}, \varepsilon_{z, t}, \varepsilon_{R, t}, \varepsilon_{\pi, t}\right]^{\prime}, \\
& \boldsymbol{\eta}_{t}=\left[\left(x_{t}-E_{t-1}\left[x_{t}\right]\right),\left(\pi_{H, t}-E_{t-1}\left[\pi_{H, t}\right]\right)\right]^{\prime} .
\end{aligned}
$$

\subsubsection{Case 4}

In Case 4, the model is:

$$
\begin{aligned}
& x_{t}=E_{t-1}\left[x_{t}\right]+\eta_{1, t}, \\
& \pi_{H, t}=E_{t-1}\left[\pi_{H, t}\right]+\eta_{2, t}, \\
& x_{t}=E_{t}\left[x_{t+1}\right]-\frac{1}{\varphi+1} r_{t}+E_{t}\left[\pi_{H, t+1}\right]+z_{t}-\frac{\varphi}{\varphi+1} r_{t}^{*}+\rho, \\
& \pi_{H, t}=\beta E_{t}\left[\pi_{H, t+1}\right]+\lambda(\varphi+1) x_{t}, \\
& r_{t}=a_{\pi} E_{t}\left[\pi_{H, t+1}\right]+a_{x} E_{t}\left[x_{t+1}\right]+\varepsilon_{r, t}, \\
& z_{t}=\rho_{z} z_{t-1}+\varepsilon_{z, t}, \\
& r_{t}^{*}=\rho_{R} r_{t-1}^{*}+\varepsilon_{R, t},
\end{aligned}
$$

which can be written as (35) with

$$
\begin{aligned}
& \mathbf{s}_{t}=\left[x_{t}, \pi_{H, t}, r_{t}, E_{t}\left[x_{t+1}\right], E_{t}\left[\pi_{H, t+1}\right], z_{t}, r_{t}^{*}\right]^{\prime}, \\
& \boldsymbol{\varepsilon}_{t}=\left[\varepsilon_{r, t}, \varepsilon_{z, t}, \varepsilon_{R, t}\right]^{\prime}, \\
& \boldsymbol{\eta}_{t}=\left[\left(x_{t}-E_{t-1}\left[x_{t}\right]\right),\left(\pi_{H, t}-E_{t-1}\left[\pi_{H, t}\right]\right)\right]^{\prime} .
\end{aligned}
$$

\subsection{Estimation Results}

We use quarterly postwar U.S. data on output, inflation, and nominal interest rates from the database, FRED, of the Federal Reserve Bank of St. Louis. We consider the following two sample periods: 1954(3) to 1971(4) and 1976(1) to 1985(4). These two periods are during and right after the Bretton Woods System, during which the U.S. was imposing capital controls. During the first sample period, the U.S. dollar was tied to gold, while after the Bretton Woods System had ended, the link to gold was terminated. The U.S. dollar became a freely floating fiat currency. The models of Case 1 and Case 3 are fitted to the data of 1976(1) to 1985(4), while Case 2 and Case 4 are fitted to the data of 1954(3) to 1971(4). 
The output gap is calculated as the log of real GDP minus the log of real potential GDP. Inflation is calculated as the log of the CPI, while the nominal interest rate is calculated as log of the Effective Federal Funds Rate, since the model is log linearized. The HP filter is used to remove a smooth trend from the output gap series.

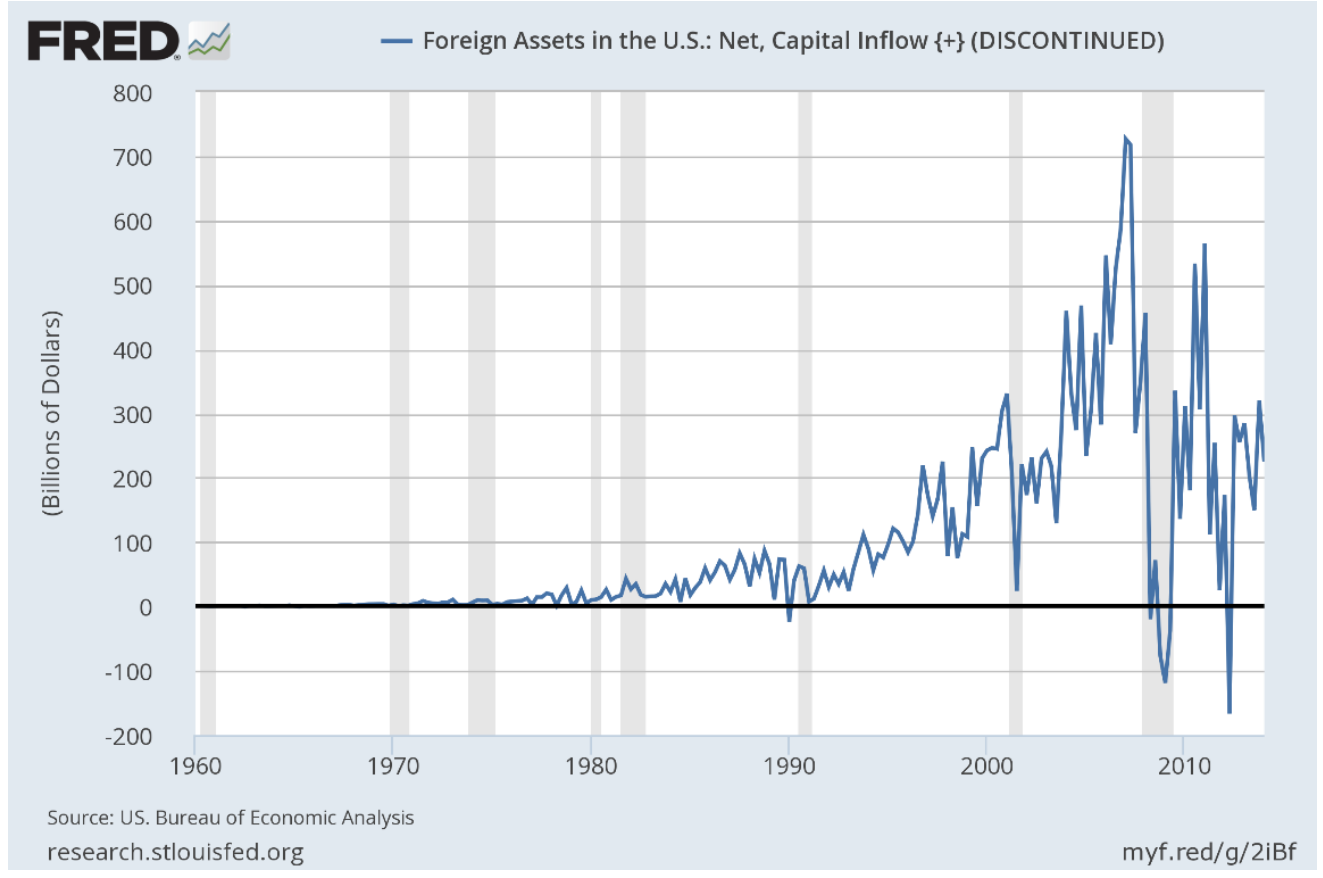

Figure 1. Foreign Assets in the U.S. (Net Capital Inflow) 


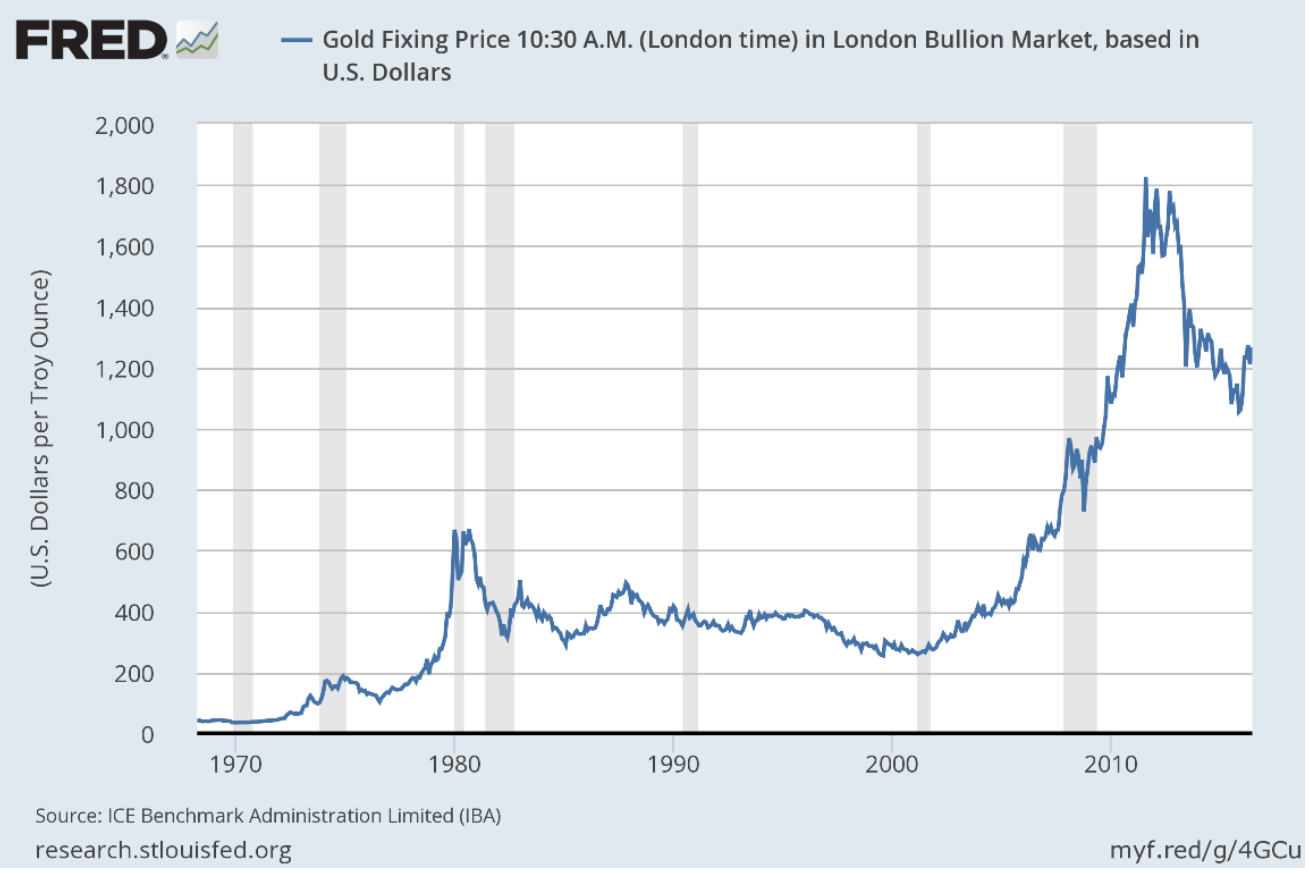

Figure 2. Gold Fixing Price in U.S. Dollars 


\subsubsection{Case 1}

Table 4. Prior Distributions

\begin{tabular}{|c|c|c|c|}
\hline Parameter & Density & Prior Mean & $\begin{array}{c}\text { Prior Standard } \\
\text { Deviation }\end{array}$ \\
\hline$a_{\pi}$ & Gamma & 0.5000 & 0.1000 \\
\hline$a_{x}$ & Gamma & 0.3000 & 0.1000 \\
\hline$\omega$ & Beta & 0.8500 & 0.1000 \\
\hline$\pi^{*}$ & Gamma & 4.0000 & 2.0000 \\
\hline$r^{*}$ & Gamma & 2.0000 & 1.0000 \\
\hline$\varphi$ & Gamma & 2.0000 & 0.7500 \\
\hline$\rho_{z}$ & Beta & 0.9000 & 0.1000 \\
\hline$\rho_{R}$ & Beta & 0.5000 & 0.2000 \\
\hline$\rho_{\pi}$ & Beta & 0.7000 & 0.1000 \\
\hline$\rho_{z R}$ & Normal & 0.0000 & 0.4000 \\
\hline$\rho_{z \pi}$ & Normal & 0.0000 & 0.4000 \\
\hline$\rho_{R \pi}$ & Normal & 0.0000 & 0.4000 \\
\hline$M_{r \zeta}$ & Normal & 0.0000 & 1.0000 \\
\hline$M_{z \zeta}$ & Normal & 0.0000 & 1.0000 \\
\hline$M_{R \zeta}$ & Normal & 0.0000 & 1.0000 \\
\hline$M_{\pi \zeta}$ & Normal & 0.0000 & 1.0000 \\
\hline$\sigma_{r}$ & Inverse Gamma & 0.2500 & 4.0000 \\
\hline$\sigma_{z}$ & Inverse Gamma & 0.8000 & 4.0000 \\
\hline$\sigma_{R}$ & Inverse Gamma & 0.1000 & 4.0000 \\
\hline$\sigma_{\pi}$ & Inverse Gamma & 0.1000 & 4.0000 \\
\hline$\sigma_{\zeta}$ & Inverse Gamma & 0.2000 & 4.0000 \\
\hline
\end{tabular}


Table 5. Determinacy versus Indeterminacy

\begin{tabular}{cc}
\hline \hline & Probability \\
\hline \hline Determinacy & Indeterminacy \\
\hline 0.1107 & 0.8893 \\
\hline
\end{tabular}

Notes: The posterior probabilities are calculated by the Metropolis-Hastings algorithm. 
Table 6. Parameter Estimation Results

\begin{tabular}{|c|c|c|c|c|}
\hline Parameter & Mean & $\begin{array}{l}\text { Standard } \\
\text { Deviation }\end{array}$ & $\begin{array}{c}90 \% \text { Posterior } \\
\text { Interval Lower } \\
\text { Bound }\end{array}$ & $\begin{array}{c}90 \% \text { Posterior } \\
\text { Interval Upper } \\
\text { Bound }\end{array}$ \\
\hline$a_{\pi}$ & 0.5002 & 0.1009 & 0.3336 & 0.6591 \\
\hline$a_{x}$ & 0.3000 & 0.0999 & 0.1371 & 0.4525 \\
\hline$\omega$ & 0.8492 & 0.0996 & 0.6861 & 1.0119 \\
\hline$\pi^{*}$ & 4.0004 & 1.9919 & 0.9583 & 6.9374 \\
\hline$r^{*}$ & 1.9997 & 1.0001 & 0.4856 & 3.4795 \\
\hline$\varphi$ & 2.0014 & 0.7494 & 0.8314 & 3.1666 \\
\hline$\rho_{z}$ & 0.8998 & 0.1001 & 0.7605 & 1.0000 \\
\hline$\rho_{R}$ & 0.4993 & 0.2003 & 0.1613 & 0.8166 \\
\hline$\rho_{\pi}$ & 0.6996 & 0.0997 & 0.5417 & 0.8664 \\
\hline$\rho_{z R}$ & -0.0035 & 0.3996 & -0.6415 & 0.6721 \\
\hline$\rho_{z \pi}$ & -0.0013 & 0.4010 & -0.6496 & 0.6676 \\
\hline$\rho_{R \pi}$ & -0.0013 & 0.3983 & -0.6478 & 0.6677 \\
\hline$M_{r \zeta}$ & 0.0009 & 0.9981 & -1.6412 & 1.6344 \\
\hline$M_{z \zeta}$ & -0.0025 & 1.0036 & -1.6662 & 1.6292 \\
\hline$M_{R \zeta}$ & 0.0026 & 1.0009 & -1.6204 & 1.6621 \\
\hline$M_{\pi \zeta}$ & -0.0037 & 1.0017 & -1.6971 & 1.5905 \\
\hline$\sigma_{r}$ & 0.3143 & 0.1636 & 0.1323 & 0.4963 \\
\hline$\sigma_{z}$ & 1.0031 & 0.5350 & 0.4320 & 1.5914 \\
\hline$\sigma_{R}$ & 0.1254 & 0.0666 & 0.0531 & 0.1988 \\
\hline$\sigma_{\pi}$ & 0.1256 & 0.0667 & 0.0539 & 0.1991 \\
\hline$\sigma_{\zeta}$ & 0.2502 & 0.1314 & 0.1082 & 0.3962 \\
\hline
\end{tabular}

Notes: The posterior summary statistics are calculated by the Metropolis-Hastings algorithm. 
8.2.2. Case 2

Table 7. Prior Distributions

\begin{tabular}{|c|c|c|c|}
\hline Parameter & Density & Prior Mean & $\begin{array}{c}\text { Prior Standard } \\
\text { Deviation }\end{array}$ \\
\hline$a_{\pi}$ & Gamma & 0.5000 & 0.1000 \\
\hline$a_{x}$ & Gamma & 0.3000 & 0.1000 \\
\hline$\omega$ & Beta & 0.9000 & 0.1000 \\
\hline$\pi^{*}$ & Gamma & 4.0000 & 2.0000 \\
\hline$r^{*}$ & Gamma & 2.0000 & 1.0000 \\
\hline$\varphi$ & Gamma & 2.0000 & 0.7500 \\
\hline$\rho_{z}$ & Beta & 0.9000 & 0.1000 \\
\hline$\rho_{R}$ & Beta & 0.5000 & 0.2000 \\
\hline$\rho_{z R}$ & Normal & 0.0000 & 0.4000 \\
\hline$M_{r \zeta}$ & Normal & 0.0000 & 1.0000 \\
\hline$M_{z \zeta}$ & Normal & 0.0000 & 1.0000 \\
\hline$M_{R \zeta}$ & Normal & 0.0000 & 1.0000 \\
\hline$\sigma_{r}$ & Inverse Gamma & 0.2500 & 4.0000 \\
\hline$\sigma_{z}$ & Inverse Gamma & 0.8000 & 4.0000 \\
\hline$\sigma_{R}$ & Inverse Gamma & 0.1000 & 4.0000 \\
\hline$\sigma_{\zeta}$ & Inverse Gamma & 0.2000 & 4.0000 \\
\hline
\end{tabular}

Table 8. Determinacy versus Indeterminacy

Probability

$\begin{array}{cc}\text { Determinacy } & \text { Indeterminacy } \\ 0.0926 & 0.9074\end{array}$

Notes: The posterior probabilities are calculated by the Metropolis-Hastings algorithm. 
Table 9. Parameter Estimation Results

\begin{tabular}{|c|c|c|c|c|}
\hline Parameter & Mean & $\begin{array}{l}\text { Standard } \\
\text { Deviation }\end{array}$ & $\begin{array}{c}90 \% \text { Posterior } \\
\text { Interval Lower } \\
\text { Bound }\end{array}$ & $\begin{array}{c}90 \% \text { Posterior } \\
\text { Interval Upper } \\
\text { Bound }\end{array}$ \\
\hline$a_{\pi}$ & 0.4998 & 0.1004 & 0.3345 & 0.6595 \\
\hline$a_{x}$ & 0.3002 & 0.0997 & 0.1432 & 0.4586 \\
\hline$\omega$ & 0.9003 & 0.1005 & 0.7345 & 1.0636 \\
\hline$\pi^{*}$ & 3.9917 & 2.0032 & 0.8760 & 6.8850 \\
\hline$r^{*}$ & 2.0021 & 1.0022 & 0.4528 & 3.4439 \\
\hline$\varphi$ & 2.0060 & 0.7488 & 0.8162 & 3.1496 \\
\hline$\rho_{z}$ & 0.8999 & 0.1001 & 0.7599 & 1.0000 \\
\hline$\rho_{R}$ & 0.4995 & 0.1997 & 0.1701 & 0.8255 \\
\hline$\rho_{z R}$ & -0.0002 & 0.3999 & -0.6489 & 0.6682 \\
\hline$M_{r \zeta}$ & 0.0025 & 0.9941 & -1.6198 & 1.6482 \\
\hline$M_{z \zeta}$ & -0.0053 & 1.0021 & -1.6673 & 1.6133 \\
\hline$M_{R \zeta}$ & 0.0015 & 1.0028 & -1.6566 & 1.6387 \\
\hline$\sigma_{r}$ & 0.3137 & 0.1673 & 0.1308 & 0.4916 \\
\hline$\sigma_{z}$ & 1.0016 & 0.5113 & 0.4258 & 1.5797 \\
\hline$\sigma_{R}$ & 0.1255 & 0.0646 & 0.0551 & 0.2006 \\
\hline$\sigma_{\zeta}$ & 0.2503 & 0.1326 & 0.1059 & 0.3939 \\
\hline
\end{tabular}

Notes: The posterior summary statistics are calculated by the Metropolis-Hastings algorithm. 
8.2.3. Case 3

Table 10. Prior Distributions

\begin{tabular}{|c|c|c|c|}
\hline Parameter & Density & Prior Mean & $\begin{array}{c}\text { Prior Standard } \\
\text { Deviation }\end{array}$ \\
\hline$a_{\pi}$ & Gamma & 0.5000 & 0.1000 \\
\hline$a_{x}$ & Gamma & 0.3000 & 0.1000 \\
\hline$\omega$ & Beta & 0.8500 & 0.1000 \\
\hline$\pi^{*}$ & Gamma & 4.0000 & 2.0000 \\
\hline$r^{*}$ & Gamma & 2.0000 & 1.0000 \\
\hline$\varphi$ & Gamma & 2.0000 & 0.7500 \\
\hline$\rho_{z}$ & Beta & 0.9000 & 0.1000 \\
\hline$\rho_{R}$ & Beta & 0.5000 & 0.2000 \\
\hline$\rho_{\pi}$ & Beta & 0.7000 & 0.1000 \\
\hline$\rho_{z R}$ & Normal & 0.0000 & 0.4000 \\
\hline$\rho_{z \pi}$ & Normal & 0.0000 & 0.4000 \\
\hline$\rho_{R \pi}$ & Normal & 0.0000 & 0.4000 \\
\hline$M_{r \zeta}$ & Normal & 0.0000 & 1.0000 \\
\hline$M_{z \zeta}$ & Normal & 0.0000 & 1.0000 \\
\hline$M_{R \zeta}$ & Normal & 0.0000 & 1.0000 \\
\hline$M_{\pi \zeta}$ & Normal & 0.0000 & 1.0000 \\
\hline$\sigma_{r}$ & Inverse Gamma & 0.2500 & 4.0000 \\
\hline$\sigma_{z}$ & Inverse Gamma & 0.8000 & 4.0000 \\
\hline$\sigma_{R}$ & Inverse Gamma & 0.1000 & 4.0000 \\
\hline$\sigma_{\pi}$ & Inverse Gamma & 0.1000 & 4.0000 \\
\hline$\sigma_{\zeta}$ & Inverse Gamma & 0.2000 & 4.0000 \\
\hline
\end{tabular}




\section{Table 11. Determinacy versus Indeterminacy}

\begin{tabular}{cc}
\hline \multicolumn{2}{c}{ Probability } \\
\hline \hline Determinacy & Indeterminacy \\
\hline 0.1144 & 0.8856 \\
\hline
\end{tabular}

Notes: The posterior probabilities are calculated by the Metropolis-Hastings algorithm. 
Table 12. Parameter Estimation Results

\begin{tabular}{|c|c|c|c|c|}
\hline Parameter & Mean & $\begin{array}{l}\text { Standard } \\
\text { Deviation }\end{array}$ & $\begin{array}{c}90 \% \text { Posterior } \\
\text { Interval Lower } \\
\text { Bound }\end{array}$ & $\begin{array}{c}90 \% \text { Posterior } \\
\text { Interval Upper } \\
\text { Bound }\end{array}$ \\
\hline$a_{\pi}$ & 0.4998 & 0.1002 & 0.3349 & 0.6597 \\
\hline$a_{x}$ & 0.3005 & 0.1002 & 0.1369 & 0.4530 \\
\hline$\omega$ & 0.8503 & 0.1008 & 0.6837 & 1.0142 \\
\hline$\pi^{*}$ & 3.9963 & 1.9854 & 0.9727 & 6.9271 \\
\hline$r^{*}$ & 1.9999 & 1.0009 & 0.4681 & 3.4823 \\
\hline$\varphi$ & 1.9971 & 0.7543 & 0.7985 & 3.1451 \\
\hline$\rho_{z}$ & 0.8996 & 0.1006 & 0.7594 & 1.0000 \\
\hline$\rho_{R}$ & 0.5001 & 0.1996 & 0.1664 & 0.8230 \\
\hline$\rho_{\pi}$ & 0.7006 & 0.0999 & 0.5443 & 0.8676 \\
\hline$\rho_{z R}$ & 0.0014 & 0.3995 & -0.6399 & 0.6689 \\
\hline$\rho_{z \pi}$ & 0.0028 & 0.3983 & -0.6546 & 0.6572 \\
\hline$\rho_{R \pi}$ & 0.0016 & 0.3987 & -0.6622 & 0.6467 \\
\hline$M_{r \zeta}$ & -0.0042 & 0.9955 & -1.6307 & 1.6422 \\
\hline$M_{z \zeta}$ & -0.0139 & 0.9987 & -1.6650 & 1.6158 \\
\hline$M_{R \zeta}$ & -0.0003 & 1.0005 & -1.6519 & 1.6362 \\
\hline$M_{\pi \zeta}$ & 0.0001 & 0.9980 & -1.6511 & 1.6273 \\
\hline$\sigma_{r}$ & 0.3118 & 0.1601 & 0.1352 & 0.4914 \\
\hline$\sigma_{z}$ & 1.0021 & 0.5104 & 0.4244 & 1.5796 \\
\hline$\sigma_{R}$ & 0.1253 & 0.0660 & 0.0538 & 0.1983 \\
\hline$\sigma_{\pi}$ & 0.1252 & 0.0656 & 0.0528 & 0.1987 \\
\hline$\sigma_{\zeta}$ & 0.2503 & 0.1311 & 0.1060 & 0.3937 \\
\hline
\end{tabular}

Notes: The posterior summary statistics are calculated by the Metropolis-Hastings algorithm. 


\subsubsection{Case 4}

Table 13. Prior Distributions

\begin{tabular}{|c|c|c|c|}
\hline Parameter & Density & Prior Mean & $\begin{array}{c}\text { Prior Standard } \\
\text { Deviation }\end{array}$ \\
\hline$a_{\pi}$ & Gamma & 0.5000 & 0.1000 \\
\hline$a_{x}$ & Gamma & 0.3000 & 0.1000 \\
\hline$\omega$ & Beta & 0.8500 & 0.1000 \\
\hline$\pi^{*}$ & Gamma & 4.0000 & 2.0000 \\
\hline$r^{*}$ & Gamma & 2.0000 & 1.0000 \\
\hline$\varphi$ & Gamma & 2.0000 & 0.7500 \\
\hline$\rho_{z}$ & Beta & 0.9000 & 0.1000 \\
\hline$\rho_{R}$ & Beta & 0.5000 & 0.2000 \\
\hline$\rho_{\mathrm{zR}}$ & Normal & 0.0000 & 0.4000 \\
\hline$M_{r \zeta}$ & Normal & 0.0000 & 1.0000 \\
\hline$M_{z \zeta}$ & Normal & 0.0000 & 1.0000 \\
\hline$M_{R \zeta}$ & Normal & 0.0000 & 1.0000 \\
\hline$\sigma_{r}$ & Inverse Gamma & 0.2500 & 4.0000 \\
\hline$\sigma_{z}$ & Inverse Gamma & 0.8000 & 4.0000 \\
\hline$\sigma_{R}$ & Inverse Gamma & 0.1000 & 4.0000 \\
\hline$\sigma_{\zeta}$ & Inverse Gamma & 0.2000 & 4.0000 \\
\hline
\end{tabular}

Table 14. Determinacy versus Indeterminacy

Probability

\begin{tabular}{cc}
\hline \hline Determinacy & Indeterminacy \\
\hline 0.0499 & 0.9501
\end{tabular}

Notes: The posterior probabilities are calculated by the Metropolis-Hastings algorithm. 
Table 15. Parameter Estimation Results

\begin{tabular}{|c|c|c|c|c|}
\hline Parameter & Mean & $\begin{array}{l}\text { Standard } \\
\text { Deviation }\end{array}$ & $\begin{array}{c}90 \% \text { Posterior } \\
\text { Interval Lower } \\
\text { Bound }\end{array}$ & $\begin{array}{c}90 \% \text { Posterior } \\
\text { Interval Upper } \\
\text { Bound }\end{array}$ \\
\hline$a_{\pi}$ & 0.4996 & 0.0997 & 0.3354 & 0.6587 \\
\hline$a_{x}$ & 0.3005 & 0.1001 & 0.1395 & 0.4547 \\
\hline$\omega$ & 0.8502 & 0.1000 & 0.6842 & 1.0115 \\
\hline$\pi^{*}$ & 3.9954 & 2.0034 & 0.9832 & 6.9734 \\
\hline$r^{*}$ & 2.0053 & 0.9997 & 0.4316 & 3.4375 \\
\hline$\varphi$ & 2.0023 & 0.7502 & 0.8059 & 3.1484 \\
\hline$\rho_{z}$ & 0.9006 & 0.0990 & 0.7623 & 1.0000 \\
\hline$\rho_{R}$ & 0.4993 & 0.1996 & 0.1683 & 0.8236 \\
\hline$\rho_{z R}$ & -0.0016 & 0.4000 & -0.6509 & 0.6632 \\
\hline$M_{r \zeta}$ & 0.0010 & 1.0040 & -1.6544 & 1.6314 \\
\hline$M_{z \zeta}$ & -0.0054 & 1.0008 & -1.6267 & 1.6727 \\
\hline$M_{R \zeta}$ & -0.0016 & 0.9949 & -1.6664 & 1.5953 \\
\hline$\sigma_{r}$ & 0.3133 & 0.1615 & 0.1337 & 0.4965 \\
\hline$\sigma_{z}$ & 1.0033 & 0.5199 & 0.4280 & 1.5854 \\
\hline$\sigma_{R}$ & 0.1254 & 0.0665 & 0.0527 & 0.1965 \\
\hline$\sigma_{\zeta}$ & 0.2508 & 0.1314 & 0.1079 & 0.3962 \\
\hline
\end{tabular}

Notes: The posterior summary statistics are calculated by the Metropolis-Hastings algorithm.

The posterior probabilities of the determinate and indeterminate regions indicate that indeterminacy is a greater risk under a fixed exchange rate regime than under a flexible exchange rate regime.

\subsection{Propagation of Shocks}

The response of three endogenous variables to one-standard deviation structural shocks are reported in Figure 3 with flexible exchange rate and current-looking monetary policy. Figure 4 contains the results with fixed exchange rates and current-looking monetary policy. Figure 5 contains the results 
with flexible exchange rates and forward-looking monetary policy. Figure 6 contains the results with fixed exchange rates and forward-looking monetary policy.

Under a flexible exchange rate regime, an unanticipated tightening of monetary policy will lead the output to decrease. Compared with forward-looking monetary policy, response of the three variables will be smaller in current-looking monetary policy. However, under a fixed exchange rate regime, output will have different responses in current-looking monetary policy and forward-looking monetary policy. With a current-looking monetary policy, output will rise after a short period, when policy interest rate is increased.

A positive technology shock will reduce the marginal costs of production, thereby increasing output and lowering inflation under both exchange rate regimes. Interest rate will also drop in response to the technology shock.

Faced with a positive foreign interest rate shock, oputput will decrease immediately in flexible exchange rate regime. While with fixed exchange rate, after a initial drop, output will bounce back, reaching a temporary higher level than the steady state. Under both exchange rate regimes, domestic inflation and interest rates will rise in response to a positive foreign interest rate shock.

Foreign inflation shock will only take effects under the flexible exchange rate regime. Domestic output will increase immediately. Domestic inflation and interest rates will drop.

In response to a sunspot shock, output, inflation, and interest rates will all increase. This reflects the fact that beliefs of higher output, inflation, and interest rates are validated by the actual increase, which is the self-fulfilling prophecy. In addition, sunspot shock has a larger effect on inflation and interest rates than on output. 
Figure 3. Impulse Response under Flexible Exchange Rate and Current-looking Monetary Policy
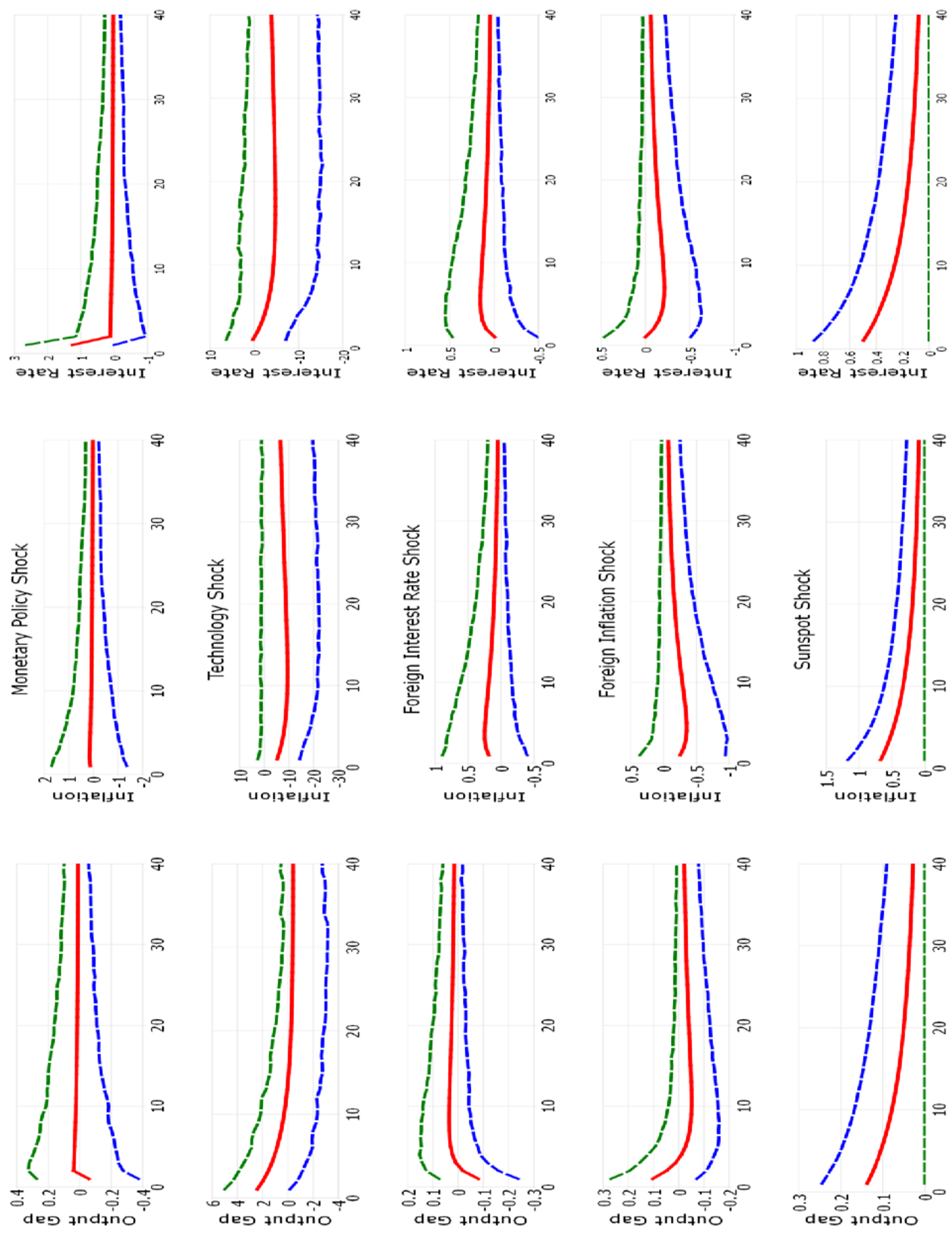
Figure 4. Impulse Response under Fixed Exchange Rate and Current-looking Monetary Policy
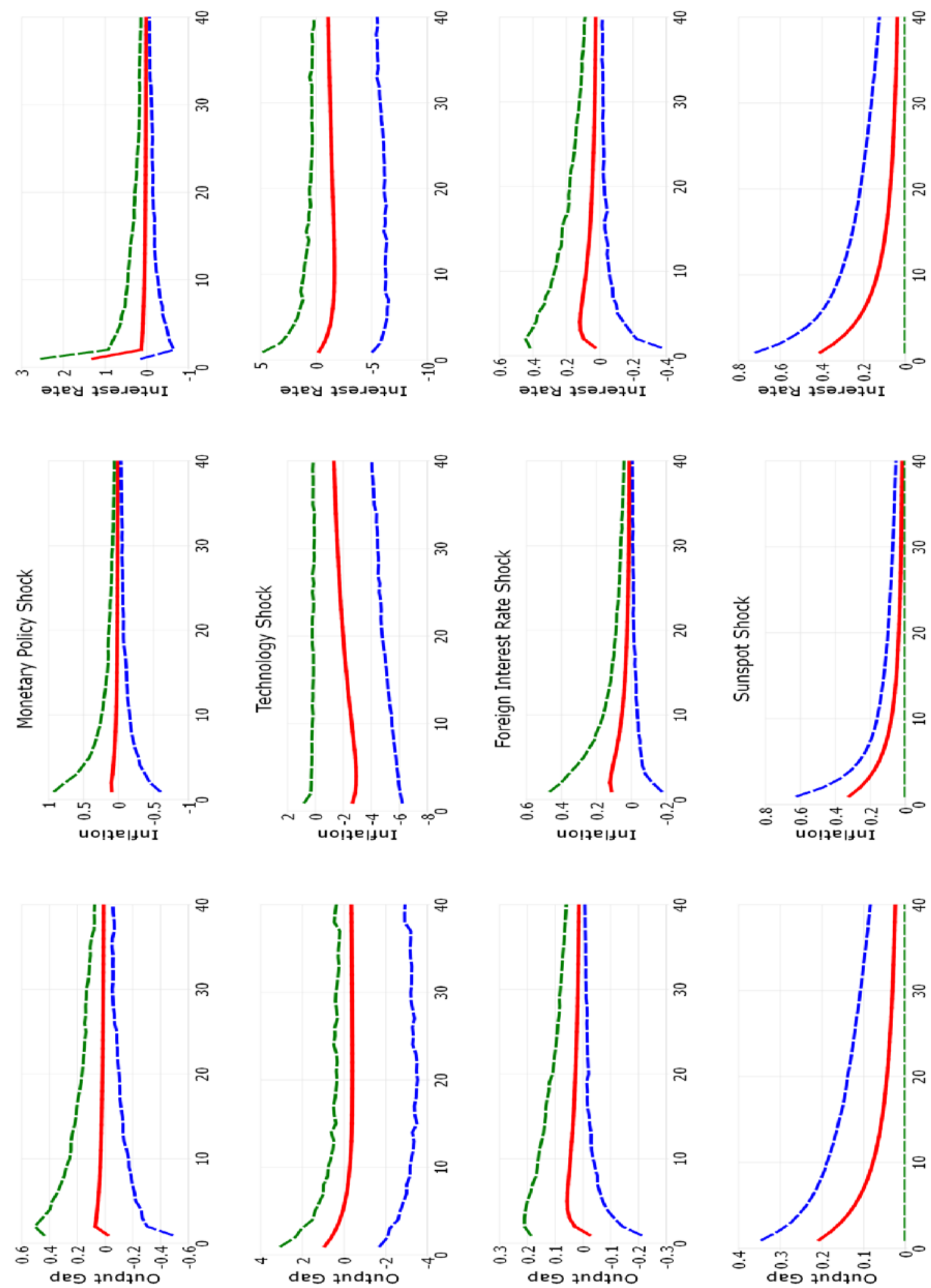
Figure 5. Impulse Response under Flexible Exchange Rate and Forward-looking Monetary Policy
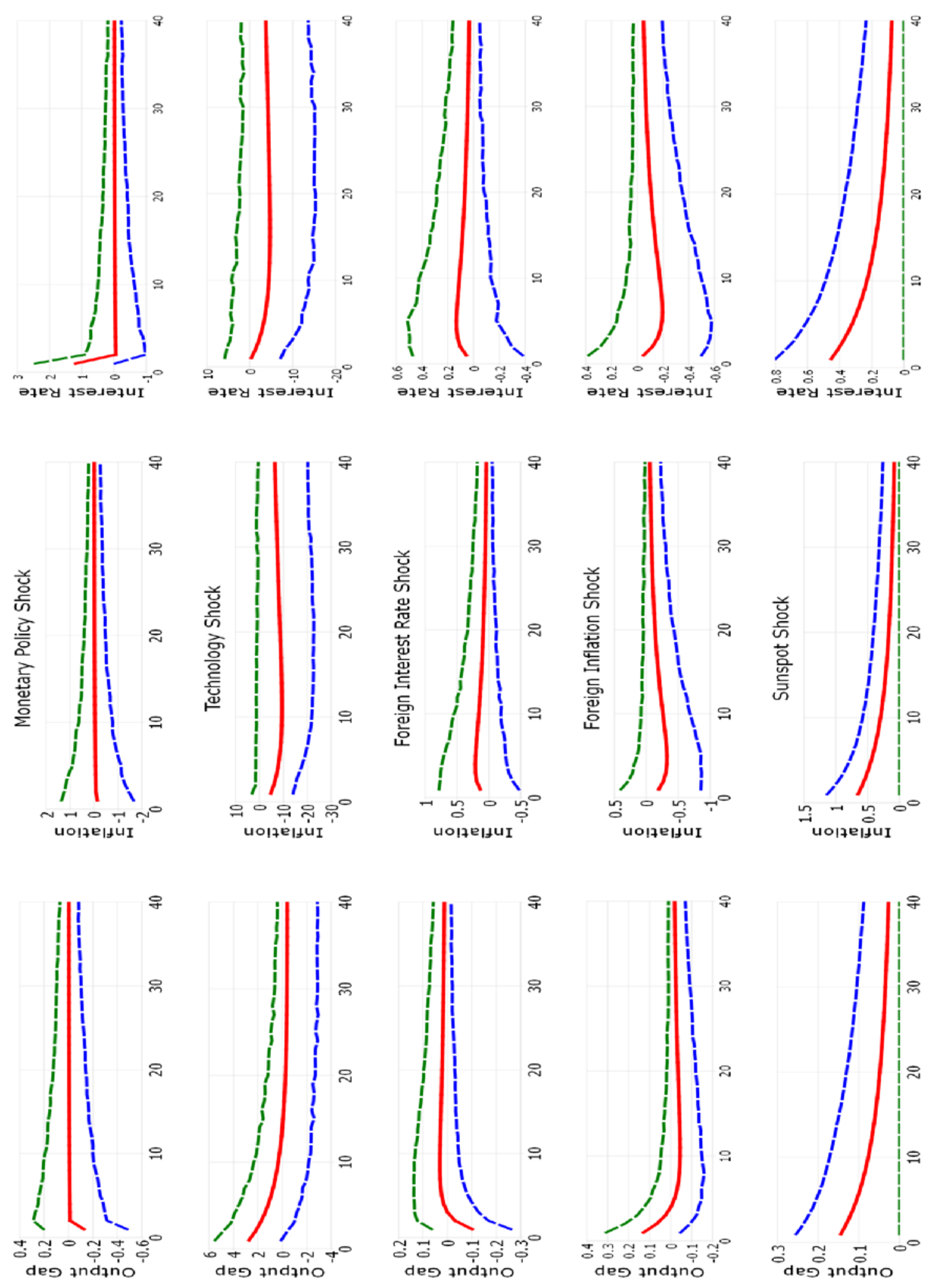
Figure 6. Impulse Response under Fixed Exchange Rate and Forward-looking Monetary Policy
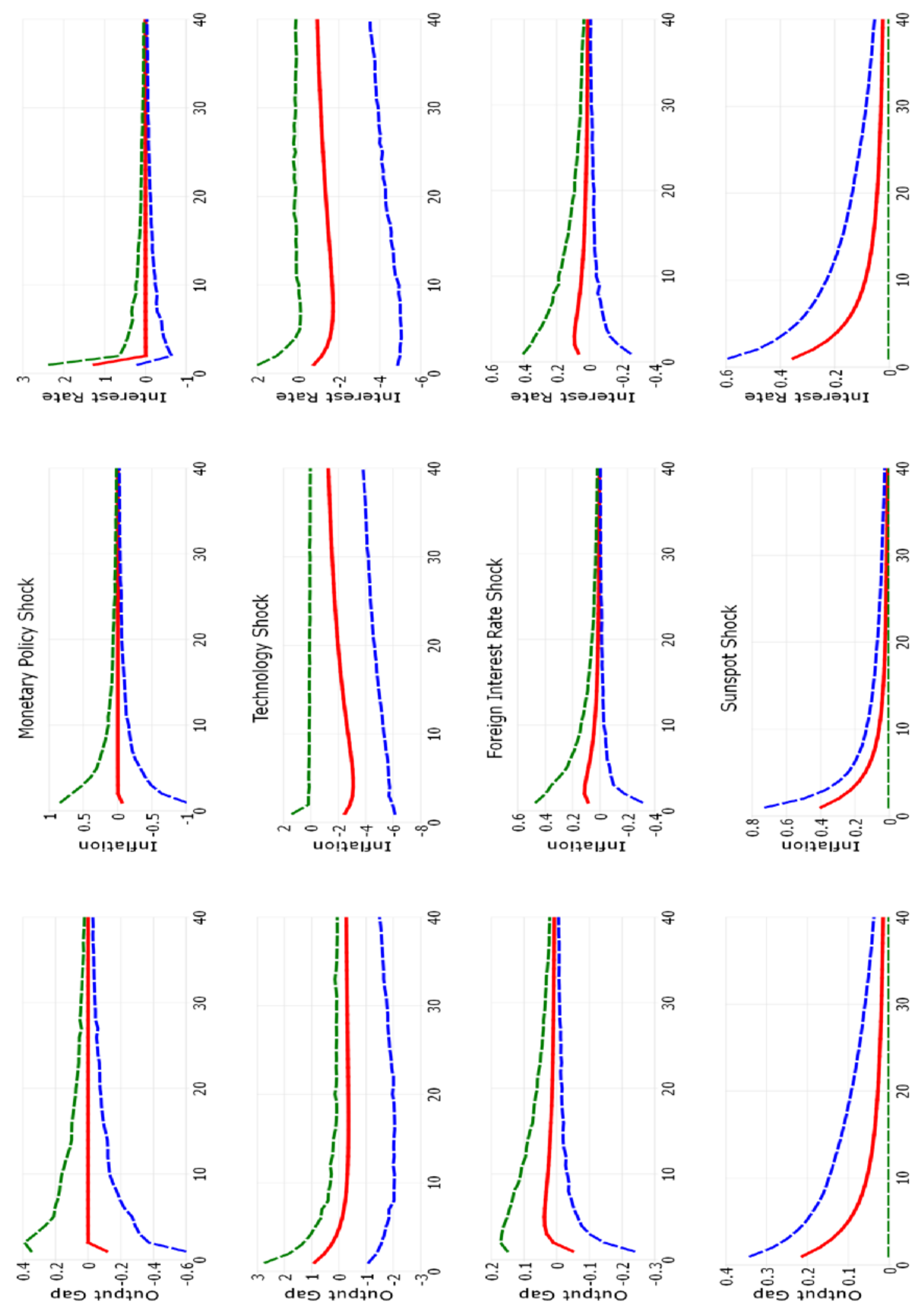


\section{Numerical Bifurcation Analysis}

In this section, we detect bifurcation numerically. In line with our former analysis, we find numerically that bifurcation exists in Case 2. We used MatContM and Mathematica to perform the computations. We find that at certain values of the deep parameters, the dynamical system becomes unstable. Several kinds of bifurcation appear at those values, both when computed forward and backward at those values. Notice that $a_{x}$ and $a_{\pi}$ are the interest rate feedbacks in the Taylor rule to the output gap and to inflation respectively. We find that when capital controls are imposed, policy makers should be cautious, when adjusting the nominal interest rate under a fixed exchange rate regime with current-looking monetary policy .

\subsection{Case 2}

To explore bifurcation phenomena in thase, we definte $a$ and $b$ such that

$$
\begin{aligned}
& a=1+\frac{a_{x}}{\varphi+1}+\frac{\varphi+2}{\beta} \\
& b=\frac{1+a_{\pi} \lambda}{\beta}+\frac{(\varphi+1)(1-\lambda)}{\beta^{2}}+\frac{a_{x}}{\beta(\varphi+1)} .
\end{aligned}
$$


Table 16. Numerical Bifurcation Results

\begin{tabular}{|c|c|c|c|c|c|}
\hline Variable & Fixed point & Eigenvalues & Origin & \multicolumn{2}{|c|}{ Bifurcation continuation } \\
\hline \multirow[t]{2}{*}{ Vary $a$} & $\begin{array}{l}\text { (1) Branch point } \\
a=4.88, b=3.88\end{array}$ & $\begin{array}{l}\text { Real and } \\
\text { positive }\end{array}$ & $\begin{array}{l}\text { Unstable } \\
\text { improper node }\end{array}$ & Backward & Branch point \\
\hline & $\begin{array}{l}\text { (2) Period doubling } \\
a=-4.88, b=3.88\end{array}$ & $\begin{array}{l}\text { Real and } \\
\text { negative }\end{array}$ & $\begin{array}{l}\text { Asymptotically } \\
\text { stable } \\
\text { improper node }\end{array}$ & Forward & $\begin{array}{l}\text { Resonance 1-2 } \\
\text { LPPD }\end{array}$ \\
\hline \multirow[t]{3}{*}{ Vary $b$} & $\begin{array}{l}\text { (3) Branch point } \\
a=4.85, b=3.85\end{array}$ & $\begin{array}{l}\text { Real and } \\
\text { positive }\end{array}$ & $\begin{array}{l}\text { Unstable } \\
\text { improper node }\end{array}$ & Backward & Branch point \\
\hline & $\begin{array}{l}\text { (4) Neutral saddle } \\
a=4.85, b=1\end{array}$ & $\begin{array}{l}\text { Real and } \\
\text { positive }\end{array}$ & $\begin{array}{l}\text { Unstable } \\
\text { improper node }\end{array}$ & & \\
\hline & $\begin{array}{l}\text { (5) Period doubling } \\
a=4.85, b=-5.85\end{array}$ & $\begin{array}{l}\text { Real with } \\
\text { opposite } \\
\text { signs }\end{array}$ & Saddle point & Backward & $\begin{array}{l}\text { LPPD } \\
\text { Resonance 1-2 }\end{array}$ \\
\hline
\end{tabular}


Figure 7. $a=4.88, b=3.88$ (Branch point) eigenvalut trace determin-

es

ant

$\{3.88$,

4.88

3.88

8.29

$1.00\}$

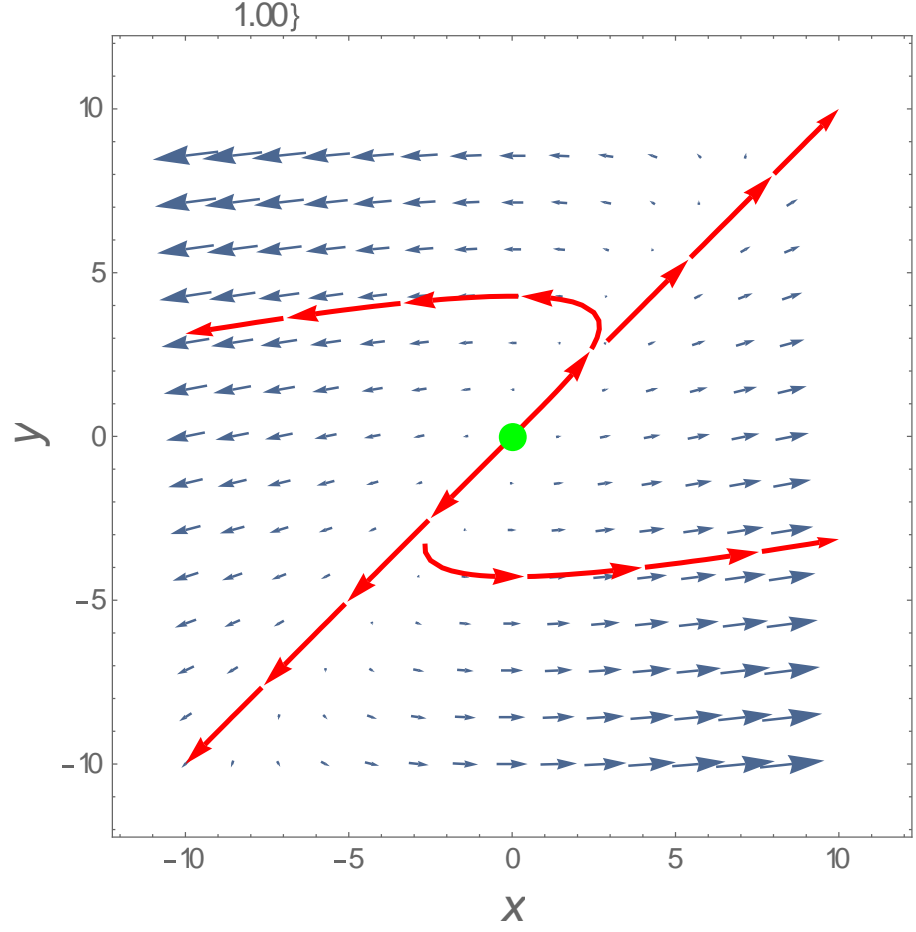


Figure 8. $a=-4.88, b=3.88($ Period doubling)

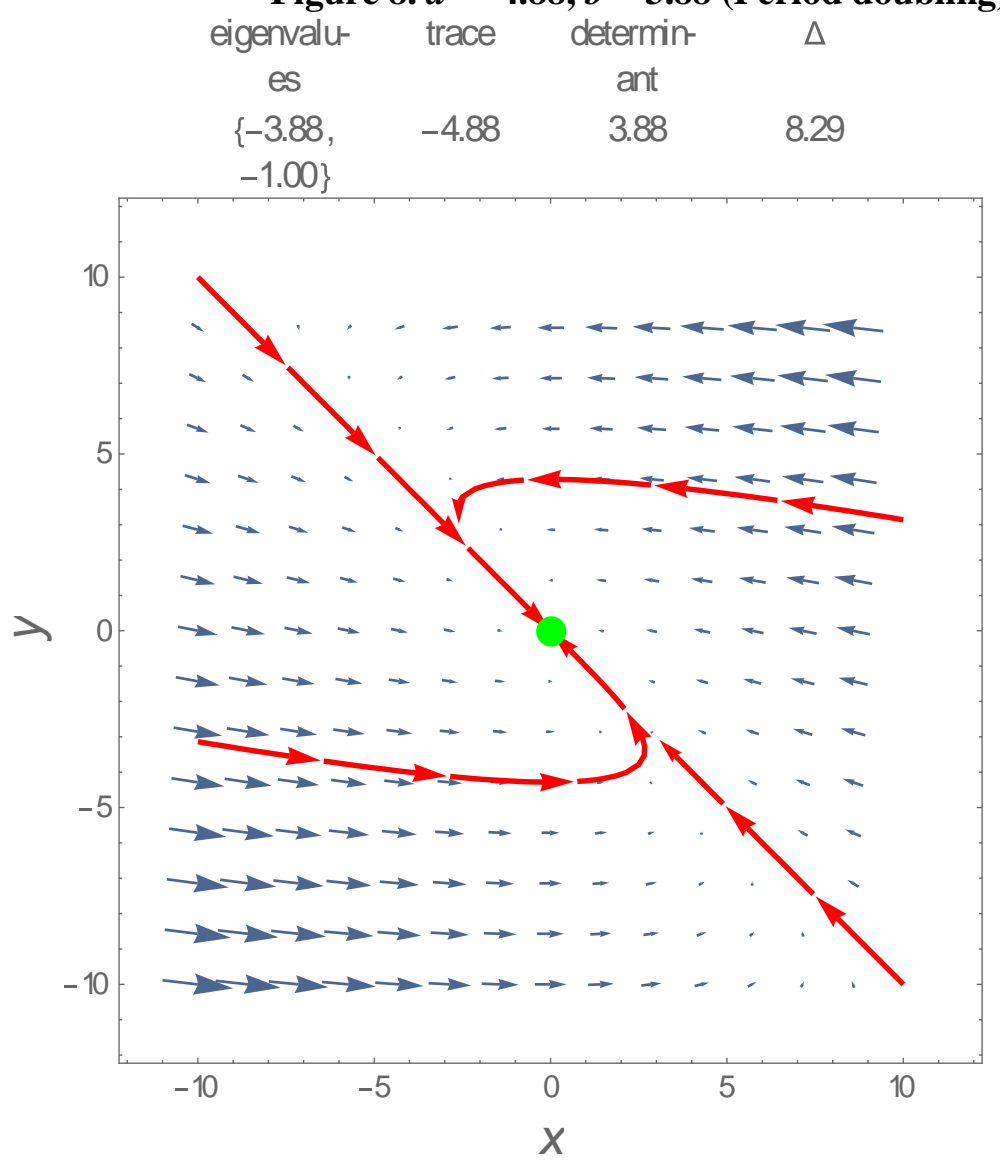


Figure 9. $a=4.85, b=3.85$ (Branch point) eigenvalu-

es trace determin-

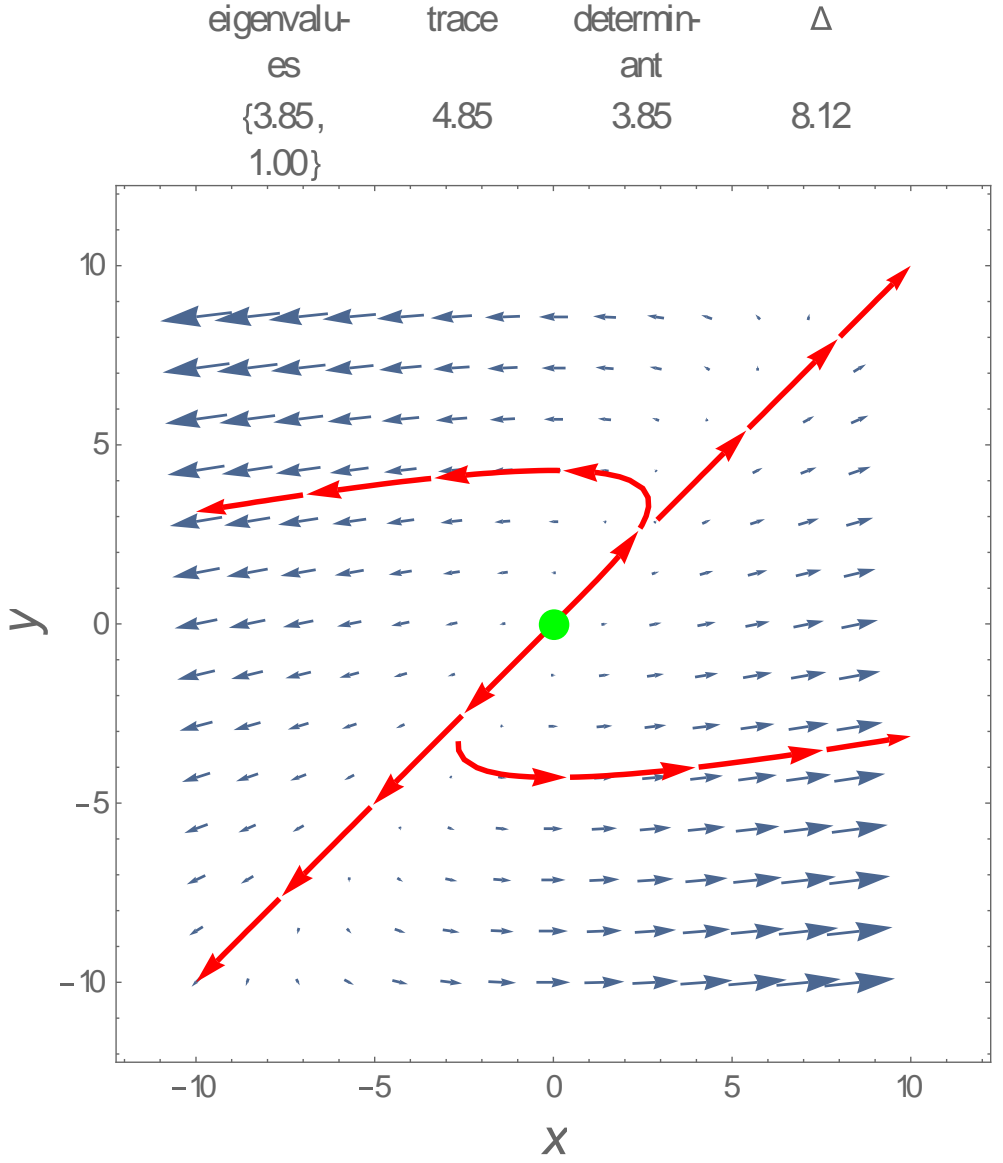


Figure 10. $a=4.85, b=1$ (Neutral saddle) eigenvalut trace determin-

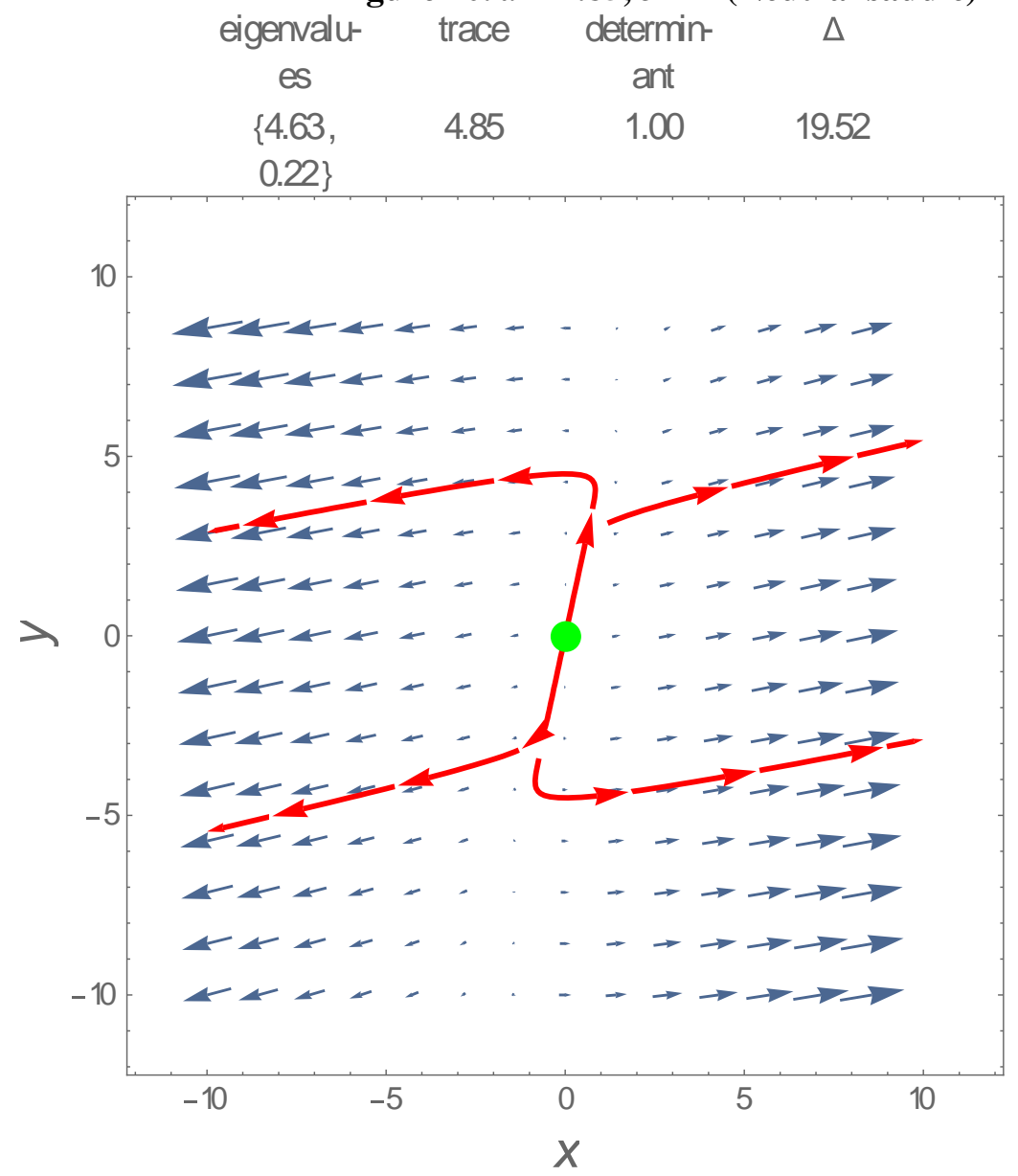


Figure 11. $a=4.85, b=-5.85$ (Period doubling)

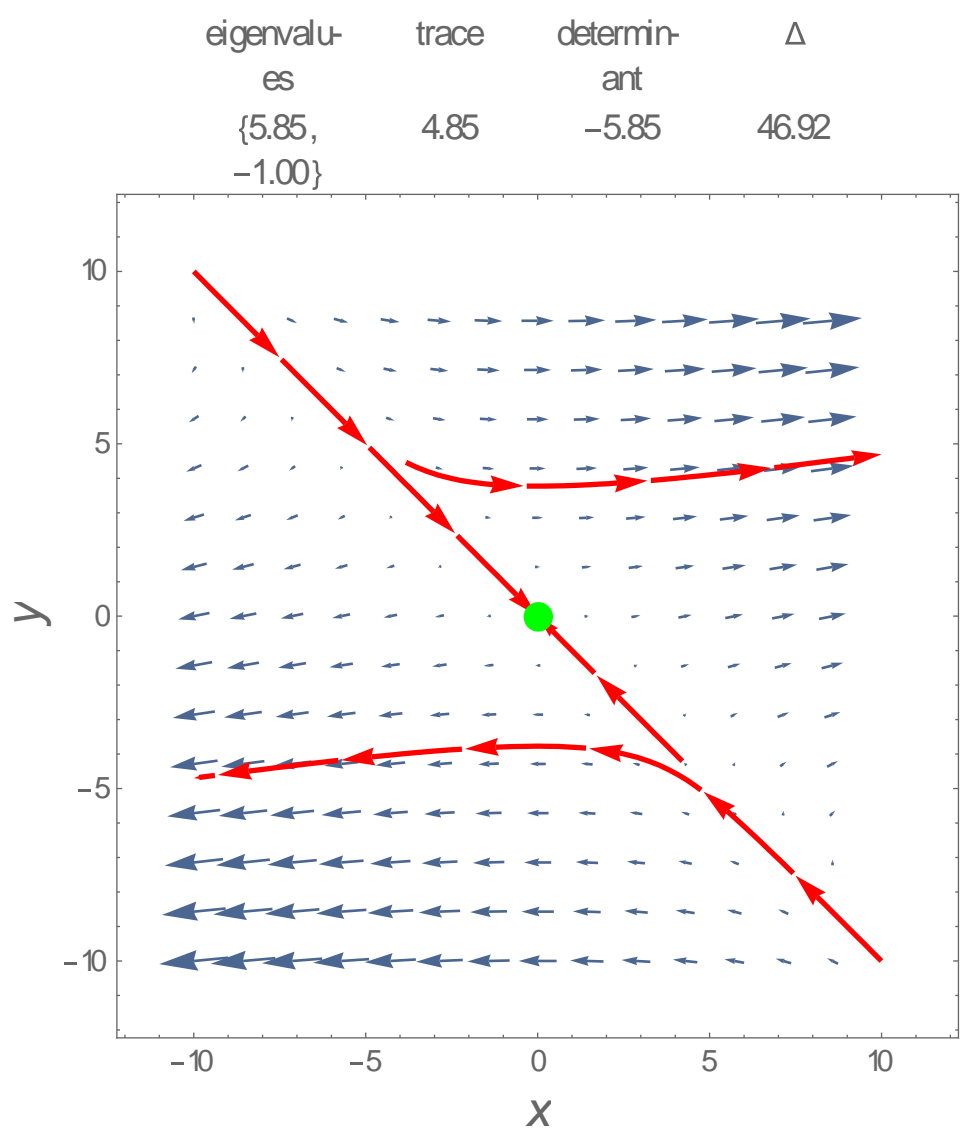




\section{Figure 12. Bifurcation Curve in the $(a, b)$-Plane}

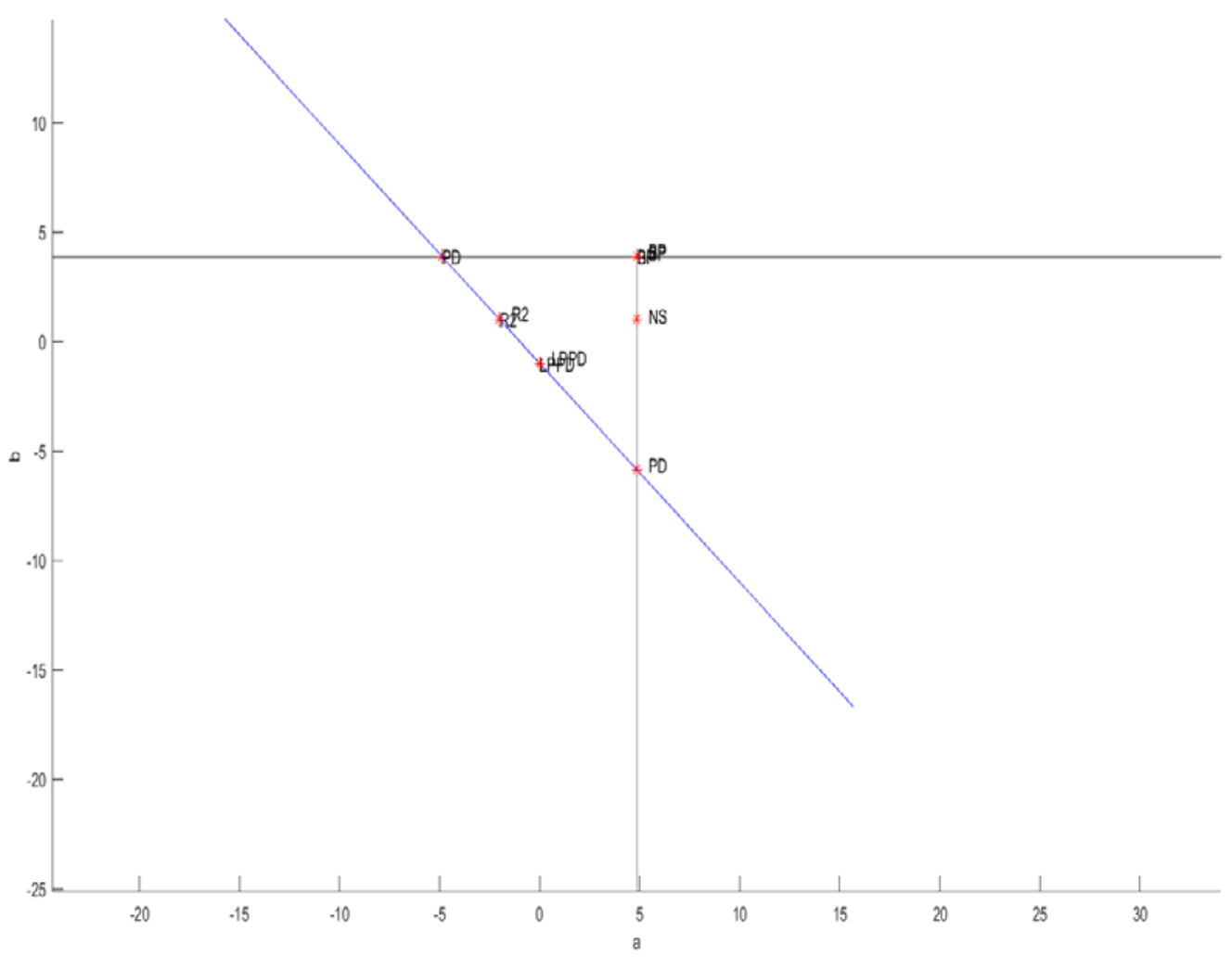

\section{Conclusion}

We investigated the dynamical properties and stability of the macroeconomy under capital controls. Conditional on different exchange rate regimes and monetary policies, we classified our analysis into four different cases. We show that under certain conditions of the deep parameters and monetary policy parameters, the macro economy will have multiple equilibria and can be unstable, especially under fixed exchange rate regimes and current-looking monetary policy. Monetary authorities need to be cautious, when they make policy decisions with capital controls. Only when taking these complexities into consideration, can macro-prudential policy with capital controls play its role in stabilizing the macro economy. The common view that capital controls can provide a simple solution to difficult problems can be seriously misguided, producing unanticipated risk. The economy could become trapped in a worse equilibrium or in an instability region, leading the economy onto a volatile path.

Under capital control, policy makers could move the economic system from indeterminate equilibria to determinate equilibrium by adjusting non-fundamental forecasting error to the set of fundamental shocks. One method, would be by changing people’s belief. An altnermative method, 
more directly under government control, would be by changing the value of policy parameters to move the system from an instability region to stability region.

We assume purchasing power parity, thereby removing terms of trade and exchange rates from the dynamical systems. Extensions of our model could permit solving for the dynamics of exchange rates and terms of trade. In addition, some of our results produce indeterminacy, and some produce deterministic business cycles without stochastic shocks. Extensions to explore stability in a stochastic economic system is a future research goal.

\section{References}

Airaudo, Marco and Luis-Felipe Zanna (2012), “Interest Rate Rules, Endogenous Cycles, and Chaotic Dynamics in Open Economies,” Journal of Economic Dynamic \& Control, Vol. 36, pp. 1566-1584.

Barnett, William A. and Guo Chen (2015), "Bifurcation of Macroeconometric Models and Robustness of Dynamical Inferences,” Foundations and Trends in Econometrics, Vol. 8(1-2), pp. 1-144.

Barnett, William A. and Evgeniya A. Duzhak (2008), “Non-robust Dynamic Inferences from Macroeconometric Models: Bifurcation Stratification of Confidence Regions,” Physica A, Vol. 387, pp. 3817-3825.

Barnett, William A. and Evgeniya A. Duzhak (2010), “Empirical Assessment of Bifurcation Regions within New Keynesian Models,” Economic Theory, Vol. 45, pp. 99-128.

Barnett, William A. and Evgeniya A. Duzhak (2014), "Structural Stability of the Generalized Taylor Rule,” Macroeconomic Dynamics, forthcoming.

Barnett, William A. and Unal Eryilmaz (2013), "Hopf Bifurcation in the Clarida, Gali, and Gertler Model,” Economic Modelling, Vol. 31, pp. 401-404.

Barnett, William A. and Unal Eryilmaz (2014), “An Analytical and Numerical Search for Bifurcations in Open Economy New Keynesian Models.” Macroeconomic Dynamics, October, pp. 1-22.

Benhabib, Jess and Roger E. A. Farmer (1999), “Indeterminacy and Sunspots in Macroeconomics.” In John Taylor and Michael Woodford (eds.), Handbook of Macroeconomics, Vol.1 Part A, Chapter 6, pp. 387-448.

Benhabib, Jess, Stephanie Schmitt-Grohé and Martín Uribe (2001), "Monetary Policy and Multiple Equilibria,” American Economic Review, Vol. 91, No. 1, pp. 167-186. 
Beyer, Andreas and Roger E. A. Farmer (2004), “On the Indeterminacy of New-Keynesian Economics,” European Central Bank Working Paper No. 323.

Beyer, Andreas and Roger E. A. Farmer (2006), “A Method to Generate Structural Impulse-Responses for Measuring the Effects of Shocks in Structural Macro Models,” European Central Bank Working Paper No. 586.

Bullard, James and Eric Schaling (2006), “Monetary Policy, Determinacy, and Learnability in the Open Economy,” European Central Bank Working Paper No. 611.

Cochrane, John H. (2011), “Determinacy and Identification with Taylor Rules,” Journal of Political Economy, Vol. 119, No. 3, pp. 565-615.

Calvo, Guillermo A. (1983), "Staggered Prices in a Utility-Maximizing Framework,” Journal of Monetary Economics, Vol. 12, pp. 383-396.

Fanelli, Luca (2012), “Determinacy, Indeterminacy and Dynamic Misspecification in Linear Rational Expectations Models,” Journal of Econometrics, Vol. 170, pp. 153-163.

Farhi, Emmanuel and Iván Werning (2014), “Dilemma not Trilemma? Capital Controls and Exchange Rate with Volatile Capital Flows,” IMF Economics Review, Vol. 62, pp. 569-605.

Farhi, Emmanuel and Iván Werning (2012), "Dealing with the Trilemma: Optimal Capital Controls with Fixed Exchange Rates,” NBER Working Paper No. 18199.

Farmer, Roger E. A., Vadim Khramov and Giovanni Nicolò (2015), "Solving and Estimation Indeterminate DSGE Models,” Journal of Economic Dynamic and Control, Vol. 54, pp. 17-36.

Fleming, J. Marcus (1962), “Domestic Financial Policies under Fixed and Floating Exchange Rates,” IMF Staff Papers, Vol 9, pp. 369-379. Reprinted in Cooper, Richard N. (ed) (1969), International Finance, New York, Penguin Books.

Franke, Reiner (1992), “Stable, Unstable, and Persistent Cyclical Behavior in a Keynes-Wicksell Monetary Growth Model,” Oxford Economic Papers, New Series, Vol.44, No.2, pp. 242-256.

Galí, Jordi and Tommaso Monacelli (2005), “Monetary Policy and Exchange Rate Volatility in a Small Open Economy,” Review of Economic Studies, Vol. 72, pp. 707-734.

Gandolfo, Giancarlo (2010), Economic Dynamics, $4^{\text {th }}$ Edition, Springer.

Korinek, Anton (2011), “The New Economics of Capital Controls Imposed for Prudential Reasons,” IMF Working Paper, WP/11/298. 
Korinek, Anton (2014), “Regulating Capital Flows to Emerging Markets: An Externality View,” Johns Hopkins University and NBER, working paper.

Kuznetsov, Yuri A. (2013), “A Tutorial for MatcontM GUI,”

http://www.staff.science.uu.nl/ kouzn101/NBA/Tutorial_MatcontMGUI.pdf.

Lubik, Thomas A. and Frank Schorfheide (2003), “Computing Sunspot Equilibria in Linear Rational Expectations Models,” Journal of Economic Dynamics and Control, Volume 28, Issue 2, pp. 273-285.

Lubik, Thomas A. and Frank Schorfheide (2004), “Testing for Indeterminacy: An Application to U.S. Monetary Policy,” American Economic Review, Vol. 94, No. 1, pp. 190-217.

Lubik, Thomas A. and Frank Schorfheide (2005), “A Bayesian Look at the New Open Economy Macroeconomics,” NBER Macroeconomics Annual, Volume 20, pp. 313-366.

Lubik, Thomas A. and Massimiliano Marzo (2007), “An Inventory of Simple Monetary Policy Rules in a New Keynesian Macroeconomic Model,” International Review of Economics and Finance, Vol. 16, pp. 15-36.

Magud, Nicolas E., Carmen M. Reinhart, and Esteban R. Vesperoni (2012), “Capital Inflows, Exchange Rate Flexibility, and Credit Booms,” IMF Working Paper, WP/12/41.

Mundell, Robert A. (1963), “Capital Mobility and Stabilization Policy under Fixed and Flexible Exchange Rates,” Canadian Journal of Economic and Political Science, Vol 29, No. 4, pp. 475-485. Reprinted in Mundell, Robert A. (1968), International Economics, New York, Macmillan..

Ostry, Jonathan D., Atish R. Ghosh, Marcos Chamon, and Mahvash S. Qureshi (2012), "Tools for Managing Financial-Stability Risks from Capital Inflows,” Journal of International Economics, Vol. 88, pp. 407-421.

Sims, Christopher A. (2002), "Solving Linear Rational Expectations Models," Computational Economics, Vol. 20, Issue 1, pp. 1-20.

Woodford, Michael (1989), “Imperfect Financial Intermediation and Complex Dynamics.” In W. A. Barnett, J. Geweke, and K. Shell (eds.), Economic Complexity: Chaos, Sunspots, Bubbles and Nonlinearity, Cambridge U. Press, Cambridge, UK, Chapter 13, pp. 309-334.

Woodford, Michael (1986), "Stationary Sunspot Equilibria in a Finance Constrained Economy,” Journal of Economic Theory, Vol. 40, pp. 128-137. 